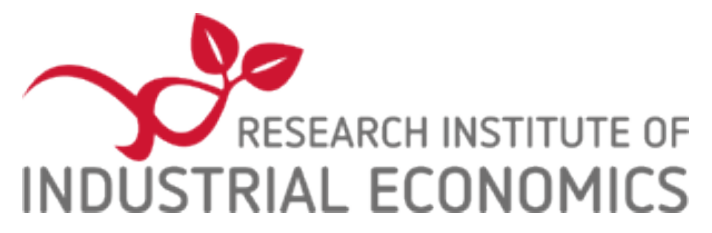

IFN Working Paper No. 1113, 2016

\title{
Market Power and Joint Ownership: Evidence from Nuclear Plants in Sweden
}

\section{Erik Lundin}




\title{
Market Power and Joint Ownership: Evidence from Nuclear Plants in Sweden
}

\author{
Erik Lundin*
}

November 4, 2019.

\begin{abstract}
This paper presents an empirical test of the anticompetitive effects of joint ownership by examining the operation of three nuclear plants in Sweden. Since maintenance is the main conduit explaining variation in output, I formulate a model of optimal maintenance allocation given three behavioral assumptions: i) maximal collusion, where all owners' profits on both nuclear and other output are maximized; ii) Cournot competition, where the majority owners' profits on both nuclear and other output are maximized; and iii) a divested solution, where all owners' profits on nuclear output are maximized, but no weight is given to non-nuclear output. The behavior that fits the data best is a "hybrid" model where maximal collusion is only achieved during periods of the year when regulatory oversight is less strict. During the remainder of the year, data is instead most consistent with the divested solution.
\end{abstract}

JEL-Classification: L13, L22, L94, D22, D43, D44

Keywords: Joint ownership, electricity wholesale market, nuclear, maintenance, collusion, regulatory threat.

\footnotetext{
*Research Institute of Industrial Economics, Box 55665, SE-102 15 Stockholm, Sweden. Email: erik.lundin@ifn.se. I would like to thank Mar Reguant, Thomas Tangerås, Pär Holmberg, Richard Friberg, Michael Pollitt, Matti Liski, Frank Wolak, Chloé Le Coq, Gordon Leslie, Gustav Karreskog, Anders Österling, Erik Lindqvist, Robert Porter, seminar participants at the Toulouse School of Economics, Stockholm School of Economics, Stanford University, Norwegian School of Economics, participants at the conferences "The Performance of Electricity Markets", "The $7^{\text {th }}$ Swedish Workshop on Competition Research", "MaCCI Annual Conference 2016", " 2016 Nordic Conference on Industrial Organization", and the "2017 IAEE Eurasian Conference" for valuable comments. Financial support by the Swedish Energy Agency, the Swedish Competition Authority, and the Jan Wallander and Tom Hedelius Foundation is greatly appreciated.
} 


\section{Introduction}

Joint ownerships are common in many markets. They may take many forms, such as joint ventures, partial mergers and acquisitions, or joint ownership of production plants. Markets in which joint ownerships have been studied include the automobile sectors in the U.S. and Japan (Alley, 1997), the U.S. airline industry Azar et al. (2018), the U.S. cellphone industry (Parker and Röller, 1997), U.S. offshore oil tracts (Hendricks and Porter, 1992), and the Dutch and US banking sectors (Dietzenbacher et al., 2000; Azar et al., 2016). In electricity markets, joint ownership arrangements are also frequent. Within the Nordic context, Amundsen and Bergman (2002) find that the increased wave of mergers and partial acquisitions that took place during the late 1990s may have affected the unilateral incentives to behave competitively, concluding that even small increases in the ownership of competing firms would have anticompetitive effects.

A number of potential efficiency gains may motivate joint ownerships, such as technological complementarities, risk sharing, or cooperation on R\&D. However, there are at least two channels by which joint ownership has anticompetitive effects: One is through promoting collusion, in that joint ownership facilitates information- and profit sharing. See Green (1980) for an analysis of how information exchange can induce collusion, and Malueg (1992) for an analysis of how the interconnection of profits induced by joint ownership may facilitate collusion. The other is through a reduction in the unilateral incentives to act competitively (Reynolds and Snapp, 1986). The reason for this is purely mechanical, in the sense that the linking of profits reduces each firm's incentive to compete. In their setting, firms own shares in each others' production plants, with one owner being the designated "controller" who decides the level of output. A key result is that in a symmetric $n$-firm Cournot equilibrium, total output will be identical to the monopoly output

if every firm controls at least $\frac{1}{n}$ of the shares in each of the other firms. Following the logic of Reynolds and Snapp, the unilaterally profit maximizing equilibrium in the present setup is therefore likely to be more competitive than the monopoly outcome, although a direct analogy to their model cannot be made since the firms examined in the current study also control a set of plants that are not jointly owned.

In this study, I consider the operation of three Swedish nuclear plants. All three plants are jointly owned by three large firms since the year 2001, although each plant has a majority owner controlling more than half of the shares. I begin by employing a difference-indifferences (DiD) estimator to show that nuclear output shifted away from the winter season in tandem with the introduction of the joint ownership, using Finnish nuclear plants as a control group. In the Nordic region, electricity demand and prices peak during the winter, creating incentives for competitive firms to allocate as much output as possible during this season. At the same time, the ability to influence the price is also greater during the winter, since the system is often capacity constrained and the price is more sensitive to reductions in output. In this exercise, I use data on monthly nuclear output from 1990-2014.

Next, I analyze a set of hourly data on nuclear output and bidding curves from the Nordic day-ahead market Elspot during 2011-2013. I begin by examining publicly available information about nuclear outages, and identify planned maintenance as the primary 
reason for the reductions in output. I then regress nuclear capacity availability, net of outages, on the slope of the inverse residual demand function facing the nuclear plants. In this test, I employ a method similar to that of Wolak (2003); McRae and Wolak (2014) and others. I find that maintenance outages respond to the slope (more maintenance is performed when the inverse residual demand function is steep), while failure outages do not.

Following these descriptive tests, I formulate a more comprehensive model of firm behavior and simulate optimal nuclear output given three behavioral assumptions: i) maximal collusion, where all owners' profits on both nuclear and other output are maximized; ii) Cournot competition, where the majority owners' profits on both nuclear and other output are maximized; and iii) a divested solution, where all owners' joint profits on nuclear output are maximized, but no weight is given to non-nuclear output. I find that maximal collusion is associated with on average 20 percent higher prices than the divested solution, while nuclear capacity utilization is 18 percent lower. In comparison to Cournot competition, differences are somewhat less pronounced.

To evaluate model fit, I regress observed output on simulated output and compare the $R^{2}$. I find that maximal collusion is only achieved during the summer period when prices are lower and regulatory oversight is less strict. During the remainder of the year, it is instead the divested solution which matches data best, i.e., a type of "hybrid" behavior, demonstrating that intensified regulatory oversight during the winter leads to relatively more competitive behavior (the regulatory environment is discussed in greater detail in Section 3.2 below). This result is robust to a range of parameter values on nuclear marginal cost, markups on non-nuclear output, forward contracting volumes, and market shares on non-nuclear output. In terms of allocative efficiency, the welfare effects of contracting nuclear output are in principle negligible due to a highly inelastic short term demand. However, productive inefficiencies arise since other thermal plants with higher marginal costs expand output. Since I only observe plant level output for the nuclear plants, it is unfortunately not possible to appropriately quantify these inefficiencies using the current modeling framework.

It is in practice impossible for an outsider to determine the level of maintenance needed to adhere the legal nuclear safety standards. Therefore, I also simulate output under a simplified dynamic extension of the model where output is only allowed to shift intertemporally between consecutive weeks, while keeping mean output constant at the observed levels. The hybrid model performs best in terms of model fit also after introducing this constraint, although differences in market outcomes across models are now naturally less pronounced.

\section{Related literature}

Structural econometric modeling of joint ownerships are relatively sparse. A likely reason is that disentangling the collusive and unilateral outcomes in a setting with joint ownership is challenging, and often relies on a comparatively parameterized framework following the work of Bresnahan (1982). In a typical setup, the goal is to estimate a "conduct parameter" 
between zero and one, where zero corresponds to perfect competition, $\frac{1}{n}$ corresponds to a symmetric $n$-firm Cournot equilibrium, and one corresponds to joint profit maximization. The conduct parameter approach has been criticized for being a poor predictor of market power, especially in dynamic settings (Tirole, 1988; Corts, 1999). An empirical example is given by Kim and Knittel (2006). Using detailed engineering data on marginal costs from the restructured Californian electricity market, they start by computing actual pricecost margins. They find that the price-cost margins implied by the conduct parameter approach usually do not reflect actual price-cost margins, since the estimated margins are highly dependent on assumptions about the functional form of the residual demand functions facing strategic firms. For a comprehensive review of empirical studies on the anticompetitive effects of joint ownerships, see Schmalz (2018).

The current study also relates to the concept of semicollusion, introduced by Steen and Sørgard (1999). They note that firms may sometimes be able to coordinate perfectly on some choice variable(s) but not on others. There are good reasons to believe that nuclear output is such a variable in the present setting. Joint ownership enhances possibilities to share information and profits. A second reason is that owners can always claim that the timing of a maintenance outage has been necessary for safety reason, which may be difficult for the regulator to verify. A third reason is that very little coordination is needed, since a single maintenance outage in a nuclear reactor may have a large effect on the price.

Another related strand of literature study market power in the Nordic electricity market. Lundin and Tangerås (2019) apply a model of Cournot competition to the Nordic dayahead market during 2011-2013 using similar data as in the present study, concluding that the average price-cost margin was around four percent. Hjalmarsson (2000) estimates a dynamic extension of the Bresnahan-Lau model using data from 1996-1999, concluding that the hypothesis of perfect competition cannot be rejected. Kauppi and Liski (2008) construct a simulation model of hydro production in the in 2000-2005, showing that a model where one strategic producer controls 30 percent of the hydro capacity fits data better than a model where hydro producers behave competitively. Damsgaard (2007) presents another simulation model that is tested on data from 2002-2006, without finding any conclusive evidence of market power other than within very limited periods. Mauritzen and Tangerås (2018) study the relationship between the day-ahead price and the intraday price, rejecting the hypothesis of perfect competition. Finally, Fogelberg and Lazarczyk (2014) study the use of capacity withholding through "voluntary" production failures to exert market power in the Nordic market in 2011-2012. They find indications of strategic withholding of fossil plants, but not nuclear or hydro plants. However, their analysis relies on a different set of identifying assumptions than the analysis in the present study, as they do not make use of bidding or production data.

Studies of unilateral market power in other electricity markets are frequent. Borenstein et al. (2002) estimates the exercise of market power in the Californian electricity market by computing the difference between actual prices and a competitive benchmark price that does not require firm conduct assumptions. Several papers study the British wholesale market: Green and Newbery (1992) find evidence of high markups and substantial deadweight losses; Wolfram (1999) follows the conduct parameter approach, finding firm 
behavior to be more competitive than theoretical models would predict, possibly due to regulatory constraints. Further, Wolak and Patrick (2001) find evidence of market power by the strategic use of capacity availability declarations, similar to the capacity withholding analyzed in the present study. The approach to measuring the ability and incentive to exercise unilateral market power using residual demand functions was introduced in Wolak (2003) and McRae and Wolak (2014), studying the wholesale markets in Australia and New Zealand, respectively.

A few studies examine the relationship between economic incentives and nuclear plant performance. The relationship between operating efficiency and deregulation is studied by Davis and Wolfram (2012). Using U.S. data from 1970-2009, they use a DiD estimator to find that deregulation and consolidation of ownership are associated with a 10 percent increase in operating efficiency. Using cross-sectional data from mainly UK and U.S. plants in 1989, Pollitt (1996) finds some evidence that regulated, privately owned nuclear plants are more efficient than publicly owned plants. In a theoretical study, Fridolfsson and Tangerås (2015) argue that incumbent producers' incentives to expand nuclear capacity in the Nordic market could be weak, since that would reduce the profitability of installed capacity. The results in the present study empirically verify that such concerns may be well grounded.

\section{Institutional background and data}

\subsection{The Nordic power exchange, Nord Pool}

The Nordic electricity markets were deregulated during the 1990s, creating a common power exchange, Nord Pool, for Norway, Denmark, Sweden and Finland. It now also includes Estonia, Latvia and Lithuania. The main auction for physical energy is the dayahead market, Elspot, in which more than 80 percent of all electricity produced in the region is sold. It has the format of a uniform price auction, and each day at noon market participants submit their bids to the auctioneer for delivery the next day. There is a separate auction each hour. Each participant submits supply or demand functions of up to 62 price steps, with a price ceiling of $2000 \mathrm{EUR} / \mathrm{MWh}$ (In 2015, the price cap was raised to $3000 \mathrm{EUR} / \mathrm{MWh}$ ). The auctioneer then sums the bids to arrive at the system supply and demand functions, and clears the market where the system supply function meets the system demand function using linear interpolation. ${ }^{1}$ This price is called the Elspot system price. Figure 1 shows an example of the system supply and demand curves.

\footnotetext{
${ }^{1} \mathrm{~A}$ unique feature of the Nordic day-ahead market is that bidders commit to bids that are convex combinations of their own submitted price-quantity pairs, which enables market clearing by linear interpolation. In addition to regular bids, participants also have the possibility to submit so-called block bids. A block bid can be distinguished from a regular bid by two characteristics. First, a block bid refers to more than one hour, and second, a bid is either accepted or not accepted as a whole. On average, five and one percent of the accepted sell- and buy volumes in the data, respectively, comes from block bids. At present, I only have data on the volume of accepted block bids, and not at which price they were bid into the market. Conveniently, both net exports and accepted block bids are entered as zero price bids by the auctioneer when computing the system price, enabling me to exactly replicate this price. On average, 6 percent of the traded volume comes from net exports.
} 
Figure 1: System supply and demand

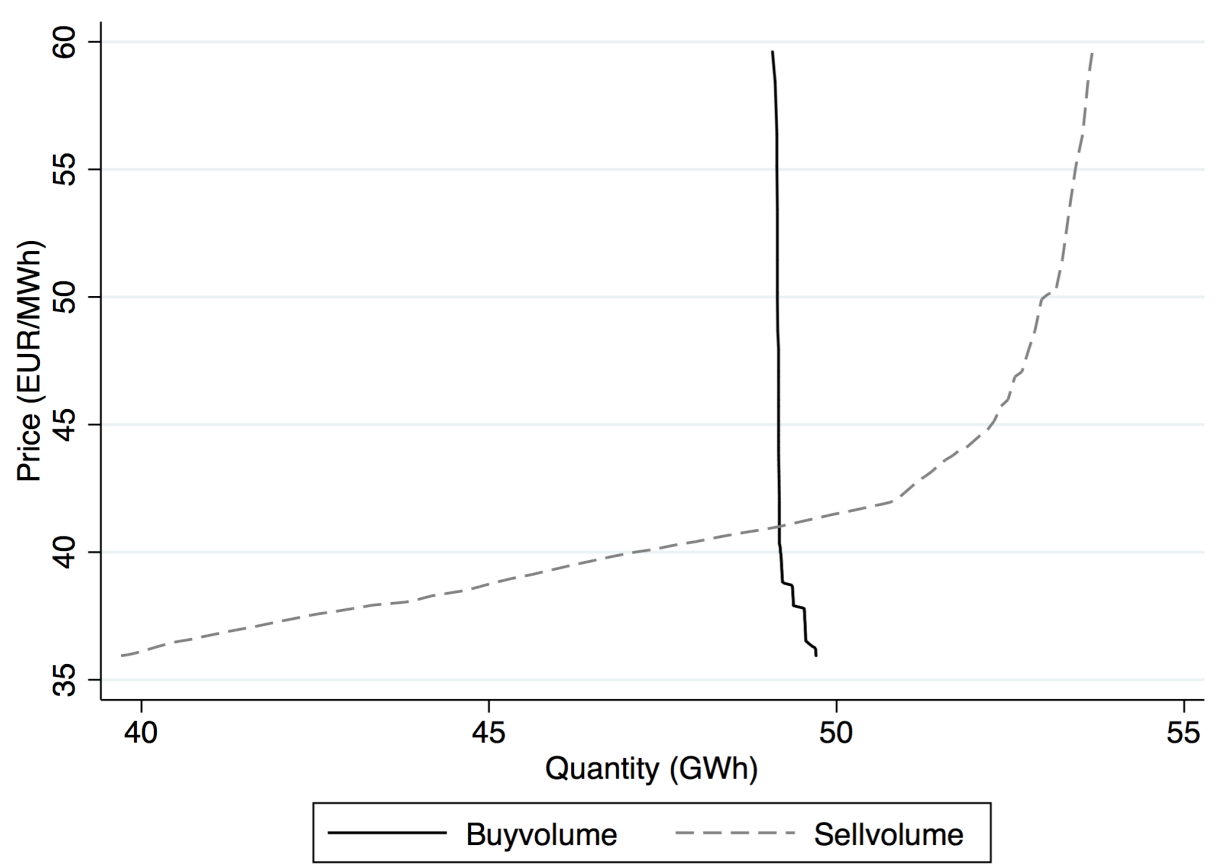

Note: System supply and demand functions on the Nordic day-ahead market Elspot during 2-3 pm, January 19, 2013. Source: Nord Pool.

In the absence of transmission constraints, all participants face the system price. When there are bottlenecks in transmission, the market may be divided into 15 different price zones depending on where the bottlenecks occur. The geographical borders of the price zones are illustrated in Figure A3. In zonal markets, bids are only tied to a specific zone, instead of a specific generation unit. This means that producers are free to meet their day-ahead obligations using any combination of their generation units located within that zone. Therefore, bidding data can only inform the data analyst of the quantity of energy supplied at different prices, but not the specific generation units that will supply that energy. All Swedish nuclear plants are located within the same price zone (SE3) which follows the system price very closely (the correlation between the system price and the price in SE3 is 0.96). Since I only have data on system level bidding curves, I can only replicate the system price and not prices in individual zones. Therefore, I use the system price as a proxy for the price received by the nuclear plant owners.

The nuclear owners sell all their output on the day-ahead market, and any obligations to deliver electricity through forward contracts are settled financially. The system price is the reference price for the main financial products. Thus, if a producer has sold a forward contract of $1 \mathrm{MWh}$ for a price of $10 \mathrm{EUR}$ and the day-ahead price is realized at $9 \mathrm{EUR} / \mathrm{MWh}$, the producer receives $1 \mathrm{EUR}$ in cash from the buyer of the contract. Forward obligations have a positive effect on the unilateral incentives to behave competitively in the day-ahead market, since increasing the day-ahead price will only increase the compensation for electricity that is not already forward contracted. Vertical integration, i.e., when a firm is active in both the wholesale and retail markets, has a similar effect 
Table 1: Installed capacity by firm and technology

\begin{tabular}{lcccc}
\hline & Total capacity $(\mathbf{G W e})$ & Vattenfall & E.ON & Fortum \\
\hline Installed nuclear capacity & \multicolumn{4}{c}{ Ownership share } \\
\hline Ringhals & $3.7(4)$ & 70 & 30 & 0 \\
Forsmark & $3.1(3)$ & 66 & 10 & 22 \\
Oskarshamn & $2.3(3)$ & 0 & 55 & 45 \\
\hline Installed non-nuclear capacity & & \multicolumn{4}{c}{ GWe } \\
\hline Hydro & 14.7 & 8.3 & 1.8 & 4.6 \\
Thermal (fossil) & 6.4 & 2.5 & 2.1 & 1.8 \\
Combined heat and power & 1.5 & 0.2 & 0.2 & 1.1 \\
Wind & 0.8 & 0.7 & 0 & 0.1 \\
\hline \hline
\end{tabular}

Note: Rows 1-3: Current ownership structure of Swedish nuclear plants. Ownership shares in percent. Two percent of Forsmark is controlled by the municipally owned power company Skellefteå Kraft (not present in the table). Rows 4-7: Installed non-nuclear capacity by technology and firm. Source: Annual reports of each firm.

when retail prices are regulated. See Wolak (2000) for a study of the competitive effects of forward contracting in the Australian wholesale market, and Bushnell et al. (2008) for a study of the competitive effects of vertical integration in three electricity markets in the U.S. The nuclear owners all have forward contracts covering around 70 percent of their generation. This figure may appear comparatively low, but retail prices are unregulated in the Nordic region and are often set as a markup over the mean day-ahead price for a certain period. Hence, price increases in the spot market are largely passed on directly to consumers.

There are five nuclear plants in the Nordic region. Three are located in Sweden and two in Finland. Vattenfall, Fortum and E.ON jointly own the Swedish plants according to the ownership structure presented in Table $1 .^{2}$ Even though Vattenfall is a state-owned Swedish firm, bonuses of executives depend on value creation rather than social welfare. More specifically, value creation is defined as return on capital employed minus the cost of capital (Vattenfall, 2013). Thus, Vattenfall should behave as a profit maximizer rather than a social planner. The nuclear plants are organized as limited liability companies, and the majority owner in each plant also has the operational responsibility for that plant (Energy Markets Inspectorate, 2010). E.ON is the only firm that owns shares in all three plants. E.ON is also the majority owner in Oskarshamn, and Vattenfall is the majority owner in Ringhals and Forsmark. Fortum owns shares in both Oskarshamn and Ringhals.

Nuclear capacity constitutes 40 percent of the nuclear owners' installed capacity. Also

\footnotetext{
${ }^{2}$ Ringhals has four reactors. The first reactor began operation in 1975 , and is a pressurized water reactor. The second reactor began operation in 1976, and is a boiling water reactor. The other reactors began operation 1981 and 1983 and are both pressurized water reactors. Forsmark has three boiling water reactors that began operation in 1980, 1981, and 1985 respectively. Oskarshamn has three reactors, all of which are boiling water reactors. The reactors began operation in 1972, 1974 and 1985. For further information about the technical characteristics of the plants, see Swedish Radiation Safety Authority (2014).
} 
Table 2: Production mix in Nord Pool

\begin{tabular}{lc}
\hline Production type & Percentage of production \\
\hline Hydro & 49 \\
Thermal (non-nuclear) & 19 \\
Swedish nuclear & 20 \\
Finnish nuclear & 7 \\
Wind & 5 \\
\hline
\end{tabular}

Note: This table presents market shares by fuel type for the Nordic market during 2011-2013. Source: Nordreg (2012).

presented in Table 1 are the nuclear owners' non-nuclear capacities by firm and technology (which differ only trivially across sample years), where hydropower constitutes the major share. Hydropower is also the dominant technology in the whole of Nord Pool (see Table 2). Each nuclear owner also owns a number of fossil-based thermal generation plants as well as a number of combined heat and power (CHP) plants. The CHP plants are primarily used for district heating and generate electricity as a by-product. Vattenfall and Fortum also own a number of wind farms (in the years following the sample period, E.ON also invested in wind power and the other firms expanded their wind capacities). In terms of market shares on actual output, the nuclear owner with the largest market share is Vattenfall (22 non-nuclear and 10 percent nuclear), followed by Fortum (9 percent non-nuclear and 4 percent nuclear), and E.ON (3 percent non-nuclear and 6 percent nuclear).

\subsection{Nuclear power in Sweden}

The current ownership structure of the nuclear plants was formed around the turn of the century. In 1999, the reactor Barsebäck 1 (with a capacity of $0.6 \mathrm{GW}$ ) was permanently shut down as a first step to phase out the Swedish reactors. ${ }^{3}$ Since Barsebäck was fully owned by the Swedish firm Sydkraft, Sydkraft acquired shares in Ringhals from Vattenfall as a compensation for the shut down, in an agreement between Sydkraft, Vattenfall, and the Swedish government. In 2001, Sydkraft acquired shares in Forsmark from Vattenfall in exchange for shares in the German energy firm HEW. Shortly afterwards, E.ON became the majority shareholder in Sydkraft. In 2000, Fortum entered the market by acquiring the Swedish firm Stora Kraft, thereby gaining ownership in both Forsmark and Oskarshamn. For further details about these M\&As, see Energy Markets Inspectorate (2006).

After some years of low wholesale prices, in 2000 nuclear production suddenly dropped simultaneously in all of the plants. Attention was brought to Vattenfall. In a radio interview (Radio Sweden, 2006), the head of production planning at Vattenfall later claimed that:

"Sometimes we reduced [nuclear] production when prices were above the variable cost...with the result that prices increased...but we never did it in

\footnotetext{
${ }^{3}$ In 2005, the remaining reactor Barsebäck 2 (with a capacity of 0.6 GW) was also shut down.
} 
agreement with the other co-owners."

Due to these events, the Swedish Competition Authority investigated suspicions of coordinated behavior, finding that up until 2002 all production decisions were planned at meetings among the owners in a way that was illegal. However, that practice had been interrupted by the time of the investigation, and the case was closed. Since 2002 each separate owner instead has the right to the available capacity in each plant net of maintenance and other outages, proportional to its ownership share. Each owner then independently requests from the plant operation manager how much of that capacity it would like to use for production (Nordic Competition Authorities, 2007). Beginning in 2002, owners have, with very few exceptions, requested that all available capacity should be used. Instead, maintenance outages have become more frequent (Swedish Competition Authorities, 2009). Specifically, it has become more common to schedule maintenance outages during the winter season (November-March) instead of in the summer.

In response to a number of price spikes during the winter of 2009-2010 due to a combination of cold weather and prolonged periods of nuclear maintenance, the Swedish government obliged owners to adopt a "Code of conduct" that explicitly regulates the type of information that can be shared among the owners (Energy Markets Inspectorate, 2010). To further impede the risk of price spikes, owners were later also obliged to only perform maintenance during the summer season (April-October) unless owners assessed it to be necessary for safety reasons. Hence, the threat of even stricter regulation in the future should incentivize owners to refrain from exerting all their available market power during the winter period. Empirical evidence that firms exercise less market power during periods of intensified regulatory oversight has previously been documented, e.g., in the context of the British electricity market (Wolfram, 1999; Wolak and Patrick, 2001). For a theoretical description of the trade-off between a monopolist's short term profits and the possibility of future regulation, see Glazer and McMillan (1992).

In contrast to many other electricity markets, maintenance plans do not have to be approved by the transmission system operator (TSO) beforehand, and the TSO has thus far never stepped in and demanded maintenance outages to be rescheduled (SvK, 2019). However, under the new EU system operation guidelines, each maintenance outage will have to be approved by the TSO (ENTSO-E, 2017). It should be noted though, that the TSO will only demand rescheduling due to network reliability issues and not market outcomes.

In terms of capacity utilization, Swedish reactors have performed worse than comparable foreign reactors after the deregulation in 1996. Figure 2 compares the trend in capacity factors ${ }^{4}$ of Swedish nuclear reactors with comparable reactors in the U.S. and the rest of Europe (excluding the former Soviet Union). ${ }^{5}$ The positive trend in capacity factors

\footnotetext{
${ }^{4}$ The capacity factor is the ratio of actual electrical energy output over a given period of time, to the maximum possible electrical energy output over that period.

${ }^{5}$ When comparing historical capacity factors of Swedish and foreign nuclear reactors, I use data from the IAEA Power Reactor Information System (IAEA, 2015). Since older reactors tend to have lower capacity factors than newer ones, only foreign reactors constructed before 1975 are included in the sample. All but two of the of the Swedish reactors were constructed after 1974, and those two reactors have been excluded. Also, all plants that have been permanently shut down are excluded. In other words, all
} 
Figure 2: International trends in nuclear capacity factors

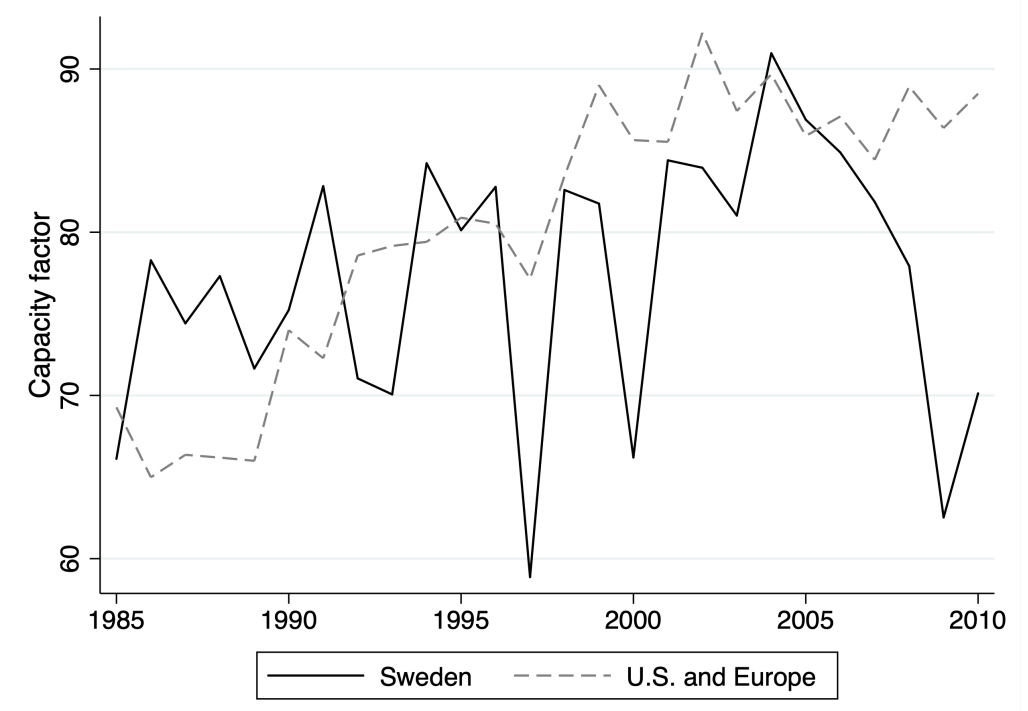

Note: Historical capacity factors of Swedish vs. U.S. and other European nuclear reactors that are currently in operation. All foreign reactors are of the same age, or older, compared to the Swedish reactors. Reactors that have been permanently shutdown are excluded. There are 41 foreign and 8 Swedish reactors included in total. Source: IAEA (2015).

that has taken place abroad has not occurred in Sweden. Comparing the years before and after Swedish deregulation, the mean capacity factor of foreign plants increased from 73 percent to 87 percent, while the mean Swedish capacity factor remained around 77 percent during both periods, with a clear drop after 2004.

Except for strategic reasons, another credible explanation for the relative drop in capacity factors is the decision in 1980 (by referendum) to gradually phase out the Swedish nuclear plants, although the only plant that has in fact been shut down is Barsebäck. The decision may have incentivized owners to refrain from large-scale investments that would mitigate the need for frequent maintenance disruptions. There is also a lack of inflow of new nuclear specialists, likely due to the common perception that the nuclear plants will be shut down at some point (SvD, 2009). Therefore, it is important to identify market power not only by examining the absolute level of output, but also its intertemporal allocation. As discussed in the introduction, in the dynamic extension of the model I therefore identify market power exclusively by comparing the intertemporal variation in output across consecutive weeks, while leaving mean output at its observed level.

Swedish reactors are of the same age or younger than the foreign ones, and should therefore have at least as high capacity factors ceteris paribus. The mean construction year of a Swedish reactor in the sample is 1979 , compared to 1972 for the foreign reactors. 


\subsection{Data}

The sample period for the main analysis is 2011-2013. Plant specific hourly generation is only available for the nuclear plants and has been compiled by the Swedish TSO Svenska Kraftnät. Swedish wind power production and the demand forecast is available for download from the homepage of the TSO (www.svk.se). System supply and demand functions, data on inflow to the hydro reservoirs, and realized Elspot prices and quantities are downloaded from the Nord Pool FTP-server and are subject to a subscription fee (Nordpool, 2019). Firm level bid data is not available. All variables are hourly, except for hydro inflow that is weekly. Nuclear fuel costs are compiled from the annual reports of each plant (OKG AB, 2014; Forsmark, 2014; Ringhals, 2014). Market shares on non-nuclear output are collected from the Nordic Energy Regulators (Nordreg, 2011, 2012, 2013). These figures differ only trivially across years. ${ }^{6}$

A unique feature of the Nordic market is that information about maintenance and failures that involve outages above $100 \mathrm{MW}$ have to be reported in the form of so-called "Urgent Market Messages" that are sent to Nord Pool. These messages are immediately made available to the public. Figure A4 shows an example of such a message. The intention of the database is to prevent participants to arbitrage on inside information, and to facilitate production planning. A similar information system is currently being implemented in all European electricity markets through a cooperation among the European energy regulators (ACER, 2015). The database is accessible to all market participants without delay. A message should preferably be posted simultaneously with, but no later than 60 minutes after, the decision for a scheduled maintenance has been made, or at the start-time for a failure. The message has to include the estimated start- and stop time of the outage, size of the outage, fuel type, as well as an identification of the plant including the owner. Information contained in a message may be updated by sending so-called follow-up messages. For example, a firm may not be able to provide accurate information about the length of a failure at the time it occurs, or may reschedule previously announced maintenance.

In total there are 467 unique events concerning the nuclear plants reported during the sample period, with an average of 4.5 messages per event. 90 percent of the outages (measured in GWh) are due to maintenance. Excluding follow-ups and failures, half of the events had been reported to the database prior to two weeks before the beginning of the outage. Since Swedish nuclear plants are constructed to operate at full available capacity, in theory it should be possible to replicate the output of each reactor just by using information from the Urgent Market Messages. It happens that output does not correspond exactly with the information provided in the messages. Some messages only contain approximations of the length of an outage. Other messages contain information about coastdowns (i.e. when a reactor gradually decreases production until the fuel in the core is depleted), and these messages do not contain information about output at each specific point in time. Still, the information contained in the messages can be used to replicate output very well, with an average absolute deviation from observed output of less than 5 percent (see Figure A5 and A6).

\footnotetext{
${ }^{6}$ Reported figures are based on actual production and include nuclear output, but since I have data on nuclear output I can compute the implied non-nuclear market shares.
} 
Table 3: Summary statistics

\begin{tabular}{lcccc}
\hline Variable & Mean & St.dev & Min & Max \\
\hline Main analysis & & & & \\
Capacity factor in Oskarshamn & 66.07 & 24.38 & 0.00 & 100 \\
Capacity factor in Ringhals & 72.02 & 25.46 & 0.00 & 100 \\
Capacity factor in Forsmark & 90.42 & 17.76 & 31.43 & 100 \\
Mean capacity factor & 76.12 & 15.32 & 35.50 & 100 \\
Total capacity availability net of maintenance & 83.24 & 14.49 & 41.05 & 100 \\
Total capacity availability net of failures & 94.55 & 5.93 & 67.02 & 100 \\
Total nuclear production & 6.98 & 1.41 & 3.25 & 9.16 \\
System clearing price & 38.78 & 14.28 & 1.38 & 224.97 \\
System clearing quantity & 35.94 & 7.27 & 19.89 & 58.16 \\
Demand forecast & 43.77 & 8.92 & 25.81 & 68.99 \\
Reservoir inflow & 23.99 & 17.93 & 2.48 & 98.54 \\
Temperature & 7.58 & 8.39 & -21.6 & 27.9 \\
Swedish wind production & .89 & .60 & .02 & 3.54 \\
\hline DiD analysis & & & & \\
Swedish capacity factor & 76.98 & 16.56 & 28.66 & 100 \\
Finnish capacity factor & 89.24 & 9.82 & 57.52 & 100 \\
\hline
\end{tabular}

Note: Capacity factors and capacity availability in percent. Nuclear production, demand forecast, reservoir inflow, and wind output in $\mathrm{GWh} / \mathrm{h}$. Clearing price in EUR/MWh. Temperature in Celsius, and wind speed in $\mathrm{m} / \mathrm{s}$. All variables in the main analysis are hourly except for reservoir inflow, which is weekly. In the DiD analysis, observations are by month.

Although firms do not report their forward positions for every point in time, the financial statements of both Vattenfall and Fortum contain information about the hedging ratio (i.e. the ratio between the volume of hedged electricity and expected physical spot market sales) for the upcoming year. For E.ON, the corresponding information is provided in yearly investor presentations released together with the annual reports (Vattenfall, 2013; Fortum, 2013; E.ON, 2014). Primarily, the firms' hedged electricity consists of futures contracts traded on the Nasdaq Commodities trading platform. Hedging ratios differ only slightly across years within firm, and are about 70 percent for both Vattenfall and Fortum, and about 80 percent for E.ON. Combined with data on the yearly market shares of each firm, I can compute the total yearly volume of forward obligations. In section 6.2, I discuss further how to allocate these contracts within each year.

The sample period for the DiD analysis is 1990-2014. Data on monthly nuclear output is available for download from Statistics Sweden and Statistics Finland respectively (Statistics Sweden, 2015; Statistics Finland, 2015). Hydro inflow to the Nordic region is available from 1995, so when including this variable the sample period is shorter. Temperature and wind speed data are available for download from the Swedish Meteorological and Hydrological Institute (SMHI, 2016).

The first part of Table 3 summarizes the variables used in the main analysis. In the table, I report capacity factors instead of actual production to make figures comparable across plants. In the analysis, I instead use actual production and capacity availability expressed in GWh. Of all Swedish plants, Oskarshamn had the lowest capacity factor, followed by 
Figure 3: Swedish and Finnish nuclear capacity factors 2011-2013

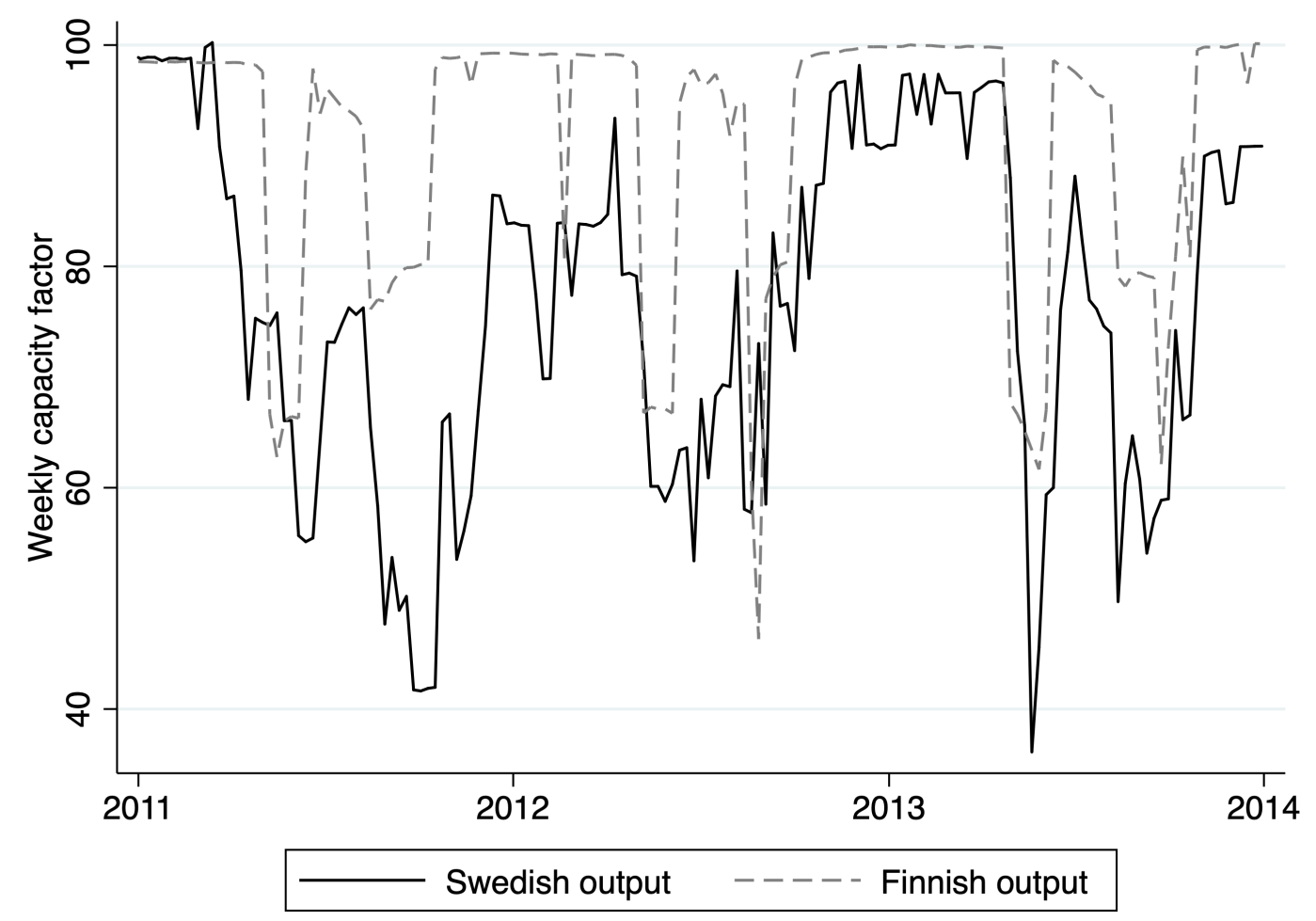

Note: Aggregate weekly nuclear capacity factors in Sweden and Finland during 2011-2013.

Ringhals and Forsmark. A closer look at the capacity factors for the aggregate output reveals that output may be fairly volatile also within a single month, which is illustrated in Figure 3. As a comparison, the corresponding figures for Finnish plants are depicted in the same figure, from which it is evident that Finnish plants operate at full capacity more often, except for limited periods of refueling during the summer season. Total capacity availability net of outages reported as maintenance is 83 percent, and the corresponding figure for failures is 95 percent, demonstrating that the majority of the output variation is due to maintenance.

The mean system clearing price is $39 \mathrm{EUR} / \mathrm{MWh}$. As depicted in Figure 1, the entire demand function is usually highly inelastic except at very low prices. The supply elasticity varies more. Nuclear and hydro production constitute base load, and are usually supplied at low prices. As demand increases, more thermal production is dispatched and the supply curve becomes steeper. As a result, in peak hours ( 8 am to $8 \mathrm{pm}$ ) the supply elasticity is generally low. The average price during a peak hour is 30 percent higher than the average price during a baseload hour, which is comparable to the price difference between the winter- and summer period. The mean clearing quantity is $36 \mathrm{GWh}$, which is about 20 percent lower than the demand forecast. This is since some of the electricity consumed is traded through bilateral contracts outside the day-ahead market (although the nuclear owners trade all their physical energy on the day-ahead market). Hydro reservoir inflow, measured in GWh of potential electricity production, is about half of the demand forecast, consistent with the fact that hydro production constitutes about half of the production 
in the market. The temperature variable measures the mean temperature in price zone SE3, i.e., where the nuclear plants are located. Geographically, this area is also centrally located in the market. The last control variable, Swedish wind production, was on average $0.89 \mathrm{GWh}$.

The second part of Table 1 summarizes the variables only used in the DiD analysis. Swedish capacity factors are about 13 percent lower than the corresponding Finnish figures. While Finnish capacity utilization has been around 90 percent throughout the sample period, the Swedish plants only reached 90 percent during one year, in 2004. 
Figure 4: Share of yearly nuclear output allocated to the winter season

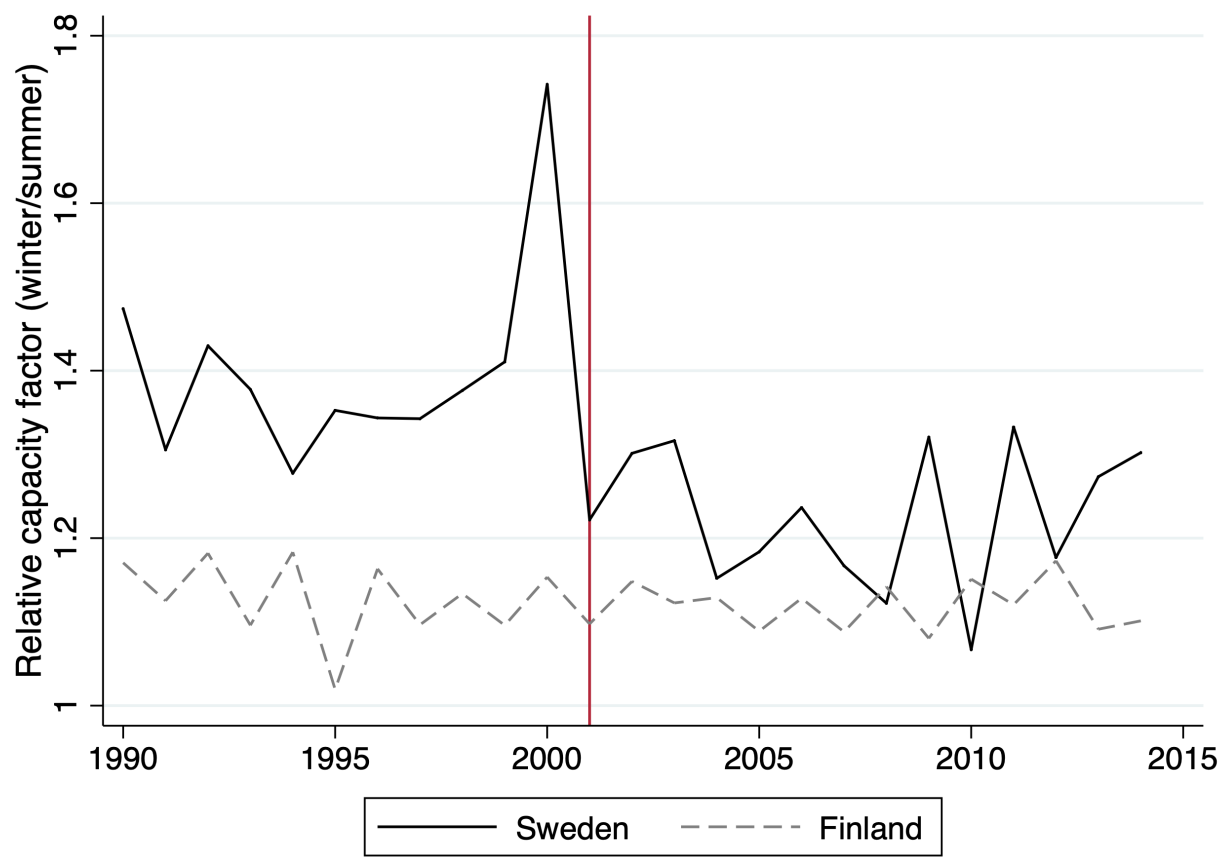

Note: Capacity factors during the winter (November-March) divided by the capacity factors during the summer (April-October) each year during 1990-2014 in Sweden and Finland. The vertical line is at the introduction of the joint ownership (2001).

\section{A descriptive DiD analysis}

Swedish nuclear output shifted away from the winter season in tandem with the introduction of the joint ownership. Figure 4 depicts the capacity factor during the winter (November-March) divided by the capacity factor during the summer (April-October) each year during 1990-2014. The vertical line (2001) is at the introduction of the joint ownership. The peak in 2000 is due to the event discussed in section 3.2, when nuclear production suddenly dropped simultaneously in all of the plants (this event took place during the summer season). By comparison, the corresponding trend for Finnish nuclear plants that did not experience a change in the ownership structure remained approximately constant. ${ }^{7}$ Since both countries' wholesale markets are interconnected, prices that firms receive after deregulation only differ trivially.

To econometrically demonstrate this shift, I estimate the model:

\footnotetext{
${ }^{7}$ It is important to note that mean Swedish capacity factors were about the same before and after the ownership change. Otherwise, a reduction in the share of output allocated to the winter season could have been achieved by simply increasing output during the summer season. Another event taking place just before the change in the ownership structure was that a small reactor accounting for about 6 percent of Swedish nuclear capacity was permanently shut down in 1999 (Barsebäck 1). However, even under the assumption that Barsebäck 1 would have produced most of its output during the summer season, the share of output allocated to the winter season would still have been higher during the post-treatment period.
} 


$$
\text { nuc }_{i y m}=\alpha+\text { Sweden }_{i}+\text { Wint }_{m}+\text { Joint }_{y}+\delta D_{i y m}+\boldsymbol{\rho}_{i y m}+\mathbf{X}_{y m} \boldsymbol{\gamma}+\varepsilon_{i y m}
$$

Where $n u c_{i y m}$ is (the logarithm of) nuclear output in country $i$ in year $y$ during month $m$, and $\alpha$ is a constant. Trends in Swedish and Finnish output throughout the sample period are depicted in Figure A1 and A2, respectively. Sweden $i$ is an indicator variable taking the value one for all Swedish observations, Wint $_{m}$ is a winter season (November - March) fixed effect, and Joint $y$ is a post-joint ownership fixed effect taking the value one for all observations after 2000. The treatment effect is captured by $\delta$, estimating the effect of the indicator variable $D_{i y m}$, which takes the value one during the winter months of the post-joint ownership period for Swedish nuclear production and zero otherwise. In addition, I include a set of country-year-winter fixed effects. In the baseline regression I include Winter $_{m} \times$ Sweden $_{i}$. In some specifications, I also include Joint $\times$ Sweden, Joint $\times$ Winter, as well as a full set of Country $\times$ Year fixed effects. Finally, $\mathbf{X}_{y m}$ is a matrix of time-varying control variables with its associated coefficient vector $\gamma$. As control variables, I include mean monthly temperature (to proxy for demand), as well as inflow to the hydro reservoirs, measured in GWh of potential output (both variables are log transformed). Both temperature and hydro inflow should have a negative impact on output: higher temperatures shift aggregate demand inwards, and higher inflow shifts residual demand inwards due to higher hydro output.

From Figure 4 it is also clear that the year with the lowest relative winter output was in 2010, i.e., around the time of the intensified regulatory oversight. In the following years, this figure increased somewhat. Figure A7 depicts Swedish capacity factors for all reactors 1990-2014 (including those that are not depicted in Figure 2), from which it is evident that also aggregate capacity factors increased after 2010, suggesting that the intensified regulatory oversight may have had a pro-competitive effect.

Results are presented in Table 4. The estimated treatment effect $\hat{\delta}$ ranges between -13 and -0.17 and is statistically significant in all specifications. The economic interpretation is that Swedish nuclear output decreased by 13 to 17 percent during the winter season of the post-joint ownership period relative to the Finnish plants, conditional on the control variables. In column (2), the interaction terms Joint $\times$ Sweden and Joint $\times$ Winter are also included as controls, and in columns (3)-(4) I also include a full set of Country $\times Y$ ear fixed effects. The covariates temperature and hydro inflow included in column (4) both have the expected negative effect on output. Placebo estimates of specification (3) are presented in Figure A8, where the year of treatment varies between 1996-2010. The greatest effects are obtained just around the time of the introduction of the joint ownership (2000-2001), consistent with the hypothesis that the joint ownership had an impact on the operation of the plants.

\section{$5 \quad$ A diagnostic test of market power}

If the nuclear owners would maximize profits on aggregate nuclear output, abstracting from forward contracts, technical constraints, and uncertainty, the first-order condition 
Table 4: DiD estimates

\begin{tabular}{|c|c|c|c|c|}
\hline & (1) & $(2)$ & $(3)$ & $(4)$ \\
\hline Treatment effect $(\delta)$ & $\begin{array}{c}-0.17^{* * *} \\
(0.022)\end{array}$ & $\begin{array}{c}-0.13^{* * *} \\
(0.029)\end{array}$ & $\begin{array}{c}-0.13^{* * *} \\
(0.030)\end{array}$ & $\begin{array}{c}-0.16^{* * *} \\
(0.038)\end{array}$ \\
\hline Joint & $\begin{array}{l}0.069^{* * *} \\
(0.016)\end{array}$ & $\begin{array}{l}* 0.095^{* * *} \\
(0.017)\end{array}$ & $\begin{array}{l}0.035^{* * *} \\
(0.0045)\end{array}$ & $\begin{array}{c}* 0.032^{* * *} \\
(0.0069)\end{array}$ \\
\hline Winter & $\begin{array}{l}0.084^{* * *} \\
(0.0049)\end{array}$ & $\begin{array}{c}* 0.085^{* * *} \\
(0.0093)\end{array}$ & $\begin{array}{c}0.085^{* * *} \\
(0.0096)\end{array}$ & $\begin{array}{r}*-0.018 \\
(0.024)\end{array}$ \\
\hline Sweden & $\begin{array}{l}0.82^{* * *} \\
(0.025)\end{array}$ & $\begin{array}{l}0.86^{* * *} \\
(0.041)\end{array}$ & $\begin{array}{c}0.60^{* * *} \\
(0.0097)\end{array}$ & $\begin{array}{l}0.58^{* * *} \\
(0.014)\end{array}$ \\
\hline Winter x Sweden & $\begin{array}{l}0.25^{* * *} \\
(0.015)\end{array}$ & $\begin{array}{l}0.23^{* * *} \\
(0.022)\end{array}$ & $\begin{array}{l}0.23^{* * *} \\
(0.023)\end{array}$ & $\begin{array}{l}0.26^{* * *} \\
(0.033)\end{array}$ \\
\hline Joint x Sweden & & $\begin{array}{r}-0.071 \\
(0.049)\end{array}$ & $\begin{array}{l}0.16^{* * *} \\
(0.012)\end{array}$ & $\begin{array}{l}0.18^{* * *} \\
(0.016)\end{array}$ \\
\hline Joint $\mathrm{x}$ Winter & & $\begin{array}{c}-0.0024 \\
(0.010)\end{array}$ & $\begin{array}{c}-0.0024 \\
(0.011)\end{array}$ & $\begin{array}{c}-0.0018 \\
(0.016)\end{array}$ \\
\hline Hydro inflow & & & & $\begin{array}{l}-0.034^{* * *} \\
(0.011)\end{array}$ \\
\hline Temperature & & & & $\begin{array}{c}-0.065^{* *} \\
(0.026)\end{array}$ \\
\hline $\begin{array}{l}\text { Country x Year } \\
\text { Observations }\end{array}$ & $\begin{array}{l}\text { No } \\
600\end{array}$ & $\begin{array}{l}\text { No } \\
600\end{array}$ & $\begin{array}{l}\text { Yes } \\
600\end{array}$ & $\begin{array}{l}\text { Yes } \\
480\end{array}$ \\
\hline
\end{tabular}

$* \mathrm{p}<.10,{ }^{* *} \mathrm{p}<0.05, * * * \mathrm{p}<0.01$

Note: Results from the DiD-estimation of eq. (1). Standard errors are clustered by year. Variables are log transformed. 


$$
p_{h d}=\underbrace{f}_{\text {marginal cost }}+\underbrace{\left|q_{h d}^{\text {nuc }} \frac{\partial p_{h d}\left(D_{h d}^{\text {res }}\right)}{\partial D_{h d}^{\text {res }}}\right|}_{\text {markup }}
$$

Where $p_{h d}$ is the equilibrium price during hour $h$ in day $d, f$ is the constant marginal cost of nuclear, $q_{h d}^{n u c}$ is the equilibrium quantity, and $\left|\frac{\partial p_{h d}\left(D_{h d}^{\text {res }}\right)}{\partial D_{h d}^{\text {res }}}\right|$ is the (absolute) slope of the inverse residual demand function facing the nuclear producers. The slope can be computed using observed bidding data following the methodology outlined by Wolak (2003); McRae and Wolak (2014). Hence, unlike other markets, this equality can be directly tested using data.

Ceteris paribus, nuclear owners perform maintenance when the price is low. Hence, there is a positive correlation between price and the markup expression in eq. (2) also when owners behave competitively. Therefore, an unconditional positive correlation between nuclear output and the markup expression does not provide evidence that owners respond to incentives to exert market power. Instead, to test if nuclear output responds to the slope component of the markup expression, I rewrite eq. (2) in logarithmic form as:

$$
\ln \left[q_{h d}^{n u c}\right]=\ln \left[p_{h d}-f\right]-\ln \left[\left|\frac{\partial p\left(D_{h d}^{r e s}\right)}{\partial D_{h d}^{r e s}}\right|\right]
$$

Which gives the optimal quantity as a function of the price net of the marginal cost and the slope. Applying this equality to data, I then use OLS to estimate the model:

$\ln \left[q_{h d}^{n u c}\right]=\alpha+\beta_{0} \ln \left[p_{h d}-f\right]+\beta_{1} \ln \left[\left|\frac{\partial p\left(D_{h d}^{r e s}\right)}{\partial D_{h d}^{r e s}}\right|\right]+\beta_{2} \ln \left(t e m p_{h d}\right)+\mathbf{X}_{h d} \boldsymbol{\gamma}+\boldsymbol{\delta}_{h}+\boldsymbol{\rho}_{m}+\varepsilon_{h d}$

Where $\alpha$ is a constant, and $\beta_{0}$ is the conditional correlation between the quantity and the price-cost margin. It suffers from reverse causality, since expanding nuclear output has a negative effect on the price. Hence, there is no economically meaningful interpretation of $\beta_{0}$. The coefficient of interest is instead $\beta_{1}$. A negative estimate of $\beta_{1}$ indicates that nuclear output responds to the slope variable beyond the impact of the price-cost margin. This coefficient should also be interpreted as the conditional correlation between the slope variable and nuclear output, and not as a causal relationship.

In the base specification I also control for temperature, since lower temperatures may lead to a higher frequency of failures or a greater need for maintenance. However, temperature is also a determinant of demand. Lower temperatures are associated with increased demand in the Nordic region due to the demand for heating (air-conditioning is virtually non-existent). Therefore, the direction of the combined temperature effect is not evident since it affects both supply and demand. Further, $\mathbf{X}_{h d}$ is a set of (log transformed) exogenous residual demand shifters with its associated coefficient vector $\boldsymbol{\gamma}$. It includes 
Figure 5: Nuclear inverse residual demand functions in February and June
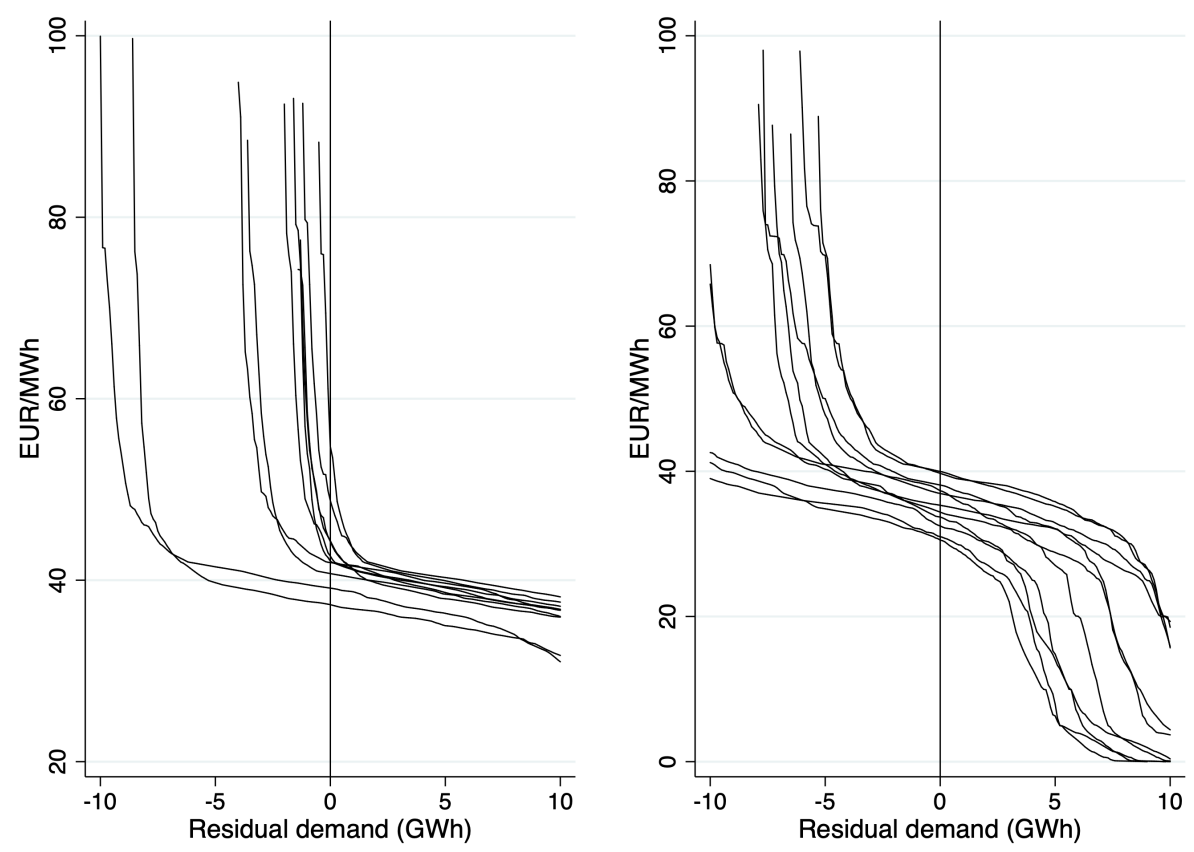

Note: Random inverse residual demand functions in February (left) and June (right) respectively, at $5 \mathrm{pm}$.

forecasted system demand, wind power output, and inflow to the hydro reservoirs (hydro inflow is only available on a weekly basis). While forecasted demand has a positive effect on residual demand, wind power output and hydro inflow both have a negative effect. The demand forecast is published by the national transmission system operators at 11:00 the day before delivery. It does not take short term price variations into account. Instead, it is determined by indicators of weather and economic activity, and should thus not suffer from reverse causality. Finally, $\boldsymbol{\delta}_{h}$ is a set of 24-hour fixed effects, $\boldsymbol{\rho}_{m}$ is a set of month-of-sample fixed effects, and $\varepsilon_{h d}$ is an error term. Standard errors are clustered by week.

\subsection{Fitting data to the model}

Dependent variable. Since I want to test the hypothesis that maintenance outages are used to exercise market power, I do not use observed nuclear output as a dependent variable directly. Instead, I compute the maximum possible output net of maintenance outages, i.e., installed capacity minus maintenance outages. The mean capacity availability net of maintenance is $7.61 \mathrm{GWh} / \mathrm{h}$ (or 83 percent), compared to the observed output of $6.98 \mathrm{GWh} / \mathrm{h}$ (or 76 percent). The correlation between the variables is 0.9 , demonstrating that maintenance is the main conduit explaining the variation in output. I also estimate the model using the corresponding figure for failures. Since failures in principle should be random events these estimates could be regarded as placebo tests, although economic incentives may also matter for how swiftly a reactor is put back online after 
a failure. The correlation between observed output and the capacity availability net of failures is 0.3 , demonstrating that failures explain less of the variation in output compared to maintenance.

Slope variable. Since data on bidding curves are only available at the system level, I assume that all nuclear output is bid into the market as inelastic bids (i.e., at zero price) in order to construct the residual demand function. Since I know that capacity utilization is close to 100 percent after netting out maintenance and failure outages this is a reasonable assumption. It is also consistent with the shape of the observed system supply function, where around half of all accepted bids are inelastic. Thus, I can construct the residual demand function of the nuclear plants according to

$$
D_{h d}^{r e s}\left(p_{h d}\right)=D_{h d}^{\text {system }}\left(p_{h d}\right)-\left[S_{h d}^{\text {system }}\left(p_{h d}\right)-q_{h d}^{\text {nuc }}\right]
$$

Where $D_{h d}^{\text {system }}\left(p_{h d}\right)$ and $S_{h d}^{\text {system }}\left(p_{h d}\right)$ are the observed system supply and demand functions. Figure 5 depicts a random set of inverse residual demand functions in February and June at $5 \mathrm{pm}$. In February the slope is generally steeper than in June, since demand is high and the system is close to full capacity utilization. To compute the slope of the inverse residual demand function in equilibrium, I take a quantity window of $0.5 \mathrm{GWh}$ on each side of the market clearing point and interpolate prices at these points to obtain two quantity/price pairs, $\left(Q_{1}, p_{1}\right)$ and $\left(Q_{2}, p_{2}\right)$. As described above, this interpolation procedure is identical to the clearing algorithm used by the auctioneer (given the volume of accepted blockbids and net exports). The (absolute) slope is then computed as $\left|\frac{\partial p\left(D_{h d}^{r e s}\right)}{\partial D_{h d}^{r e s}}\right|=\left|\frac{p_{1}-p_{2}}{Q_{1}-Q_{2}}\right| .8$ The mean slope is 2.6, meaning that a one GWh contraction of nuclear output will result in a $2.6 \mathrm{EUR} / \mathrm{MWh}$ increase in the equilibrium price. Due to some very high values, the distribution is skewed with a few exceptionally large outliers. Conversely, the distribution of its logarithm is much less skewed, mitigating the possibility that a few outliers drive the result (see Figure A9 for a density plot).

Another figure of interest is the corresponding elasticity: multiplying the slope by $\frac{q_{h d}^{n u c}}{p_{h d}}$ gives the percentage increase in the price as a result of a one percent contraction of nuclear output. The mean of this figure is 0.43 , meaning that a one percent contraction would on average lead to a 0.43 percent increase in the price. Since nuclear output constitutes about half of the nuclear owners' total output, the mean elasticity with respect to the nuclear owners' total output is about 0.86 .

Price-cost margin. I approximate the marginal cost $f$ by the mean accounted fuel cost for all plants during the sample period. This amounts to EUR 5/MWh, corresponding to 13 percent of the mean day-ahead price (fuel costs differ only trivially across plants and years). The fuel cost depends both on the direct cost of fuel, which was on average EUR 3.5/MWh, and a mandatory depository fee based on the amount of electricity produced, which was EUR 1.5/MWh. The nuclear producers also pay a nuclear tax based on the installed capacity of each reactor. However, a reactor is only exempted from the tax if it remains inactive for more than three months. Therefore this tax should not be considered

\footnotetext{
${ }^{8}$ The interpolation procedure is identical to the clearing algorithm used by the auctioneer, since all bids are piecewise linear (apart from the blockbids). As a robustness test I also compute the slope by using a quantity window of 0.25 and $1 \mathrm{GWh}$, respectively. The correlations between all slope measures are above 0.85 , confirming that the size of the window is not crucial.
} 
as a variable cost. Further, I do not consider the cost of labor or capital as variable costs, since these costs are in principle invariant to the amount of maintenance performed.

\section{$5.2 \quad$ Results}

Results are presented in Table 5 . When the dependent variable is nuclear capacity net of maintenance outages in columns (1)-(3), the slope variable is negative and precisely estimated in all specifications. It is only trivially affected by the other regressors, indicating that nuclear output responds to incentives to exercise market power. When the month-of-sample fixed effects are replaced by week-of-sample fixed effects in column (4), the slope coefficient becomes much smaller and is imprecisely estimated, indicating that owners do not respond to short term variations in incentives to exert market power. In columns (5)-(8), the dependent variable is instead capacity availability net of failures. The slope coefficient then becomes small and is imprecisely measured in all specifications, indicating that failures are not used to exercise market power.

Turning to the control variables, the price coefficient is negative and precisely estimated in columns (1)-(4), indicating reverse causality. The temperature variable is imprecisely measured in all specifications but (3), where it is positive. The demand forecast coefficient has the expected positive sign in (2), indicating that less maintenance is performed when demand is high, but when including also hydro inflow in (3) it becomes smaller and imprecisely measured. The wind power variable is positive and precisely estimated in (2)-(3), which is somewhat counterintuitive since an expansion of wind power should have a negative effect on residual demand. However, strong winds may also have a positive effect on demand due to an increased need for heating (which is only partly accounted for when computing the demand forecast due to forecasting errors), which could help explain the positive coefficient. The last control variable, hydro inflow, has the expected negative sign in all specifications where it is included (since it is only available by week, it cannot be included alongside the week-of-sample fixed effects). Since increased hydro inflow is synonymous with a negative residual demand shock, this indicates that more maintenance is performed when the price is low. Hydro inflow is also the only control variable that has a non-trivial effect on the volume of failures, demonstrating that failures are fixed more swiftly when residual demand (and thereby the price) is high. Hence, failures are not completely random events, although they react more subtly to economic incentives than planned maintenance outages. 
Table 5: Determinants of nuclear outages

\begin{tabular}{|c|c|c|c|c|c|c|c|c|}
\hline & \multicolumn{4}{|c|}{ Dep var: Capacity net of maintenance } & \multicolumn{4}{|c|}{ Dep var: Capacity net of failures } \\
\hline & (1) & $(2)$ & (3) & (4) & $(5)$ & (6) & (7) & (8) \\
\hline Slope & $\begin{array}{r}-0.013^{*} \\
(0.0037\end{array}$ & $\begin{array}{l}* * * *-0.012^{* *} \\
7)(0.0020)\end{array}$ & $\begin{array}{l}* * 0.011^{* * *} \\
(0.0020) \\
(1)\end{array}$ & $\begin{array}{c}* 0.00024 \\
(0.0011)\end{array}$ & $\begin{array}{r}0.0015 \\
(0.0012\end{array}$ & $\begin{array}{lr}5 & 0.00084 \\
2) & (0.00089\end{array}$ & $\begin{array}{ll}4 & 0.0011 \\
9) & (0.00090)\end{array}$ & $\begin{array}{r}0.00022 \\
0)(0.00059)\end{array}$ \\
\hline Price & & $\begin{array}{r}-0.022^{*} \\
(0.011)\end{array}$ & $\begin{array}{c}*-0.027^{* *} \\
(0.011)\end{array}$ & $\begin{array}{c}-0.024^{* *} * \\
(0.0054)\end{array}$ & & $\begin{array}{c}0.0064 \\
(0.0052)\end{array}$ & $\begin{array}{c}0.0051 \\
(0.0051)\end{array}$ & $\begin{array}{c}-0.0028 \\
(0.0025)\end{array}$ \\
\hline Temperature & & $\begin{array}{c}0.016 \\
(0.015)\end{array}$ & $\begin{array}{c}0.038^{* *} \\
(0.015)\end{array}$ & $\begin{array}{c}-0.010 \\
(0.0082)\end{array}$ & & $\begin{array}{r}-0.0078 \\
(0.010)\end{array}$ & $\begin{array}{r}-0.0017 \\
(0.010)\end{array}$ & $\begin{array}{c}0.0035 \\
(0.0083)\end{array}$ \\
\hline Demand forecast & & $\begin{array}{r}0.11^{* *} \\
(0.043)\end{array}$ & $\begin{array}{c}0.038 \\
(0.040)\end{array}$ & $\begin{array}{c}0.047 \\
(0.029)\end{array}$ & & $\begin{array}{r}-0.0019 \\
(0.021)\end{array}$ & $\begin{array}{c}-0.021 \\
(0.022)\end{array}$ & $\begin{array}{c}0.0090 \\
(0.013)\end{array}$ \\
\hline Wind power & & $\begin{array}{r}0.010^{*-} \\
(0.0033)\end{array}$ & $\begin{array}{l}* * 0.012^{* * *} \\
(0.0033)\end{array}$ & $\begin{array}{c}* \quad 0.0023 \\
(0.0020)\end{array}$ & & $\begin{array}{c}-0.0027 \\
(0.0018)\end{array}$ & $\begin{array}{c}-0.0023 \\
(0.0018)\end{array}$ & $\begin{array}{r}-0.00027 \\
(0.0013)\end{array}$ \\
\hline Hydro inflow & & & $\begin{array}{c}-0.054^{* * *} \\
(0.010)\end{array}$ & & & & $\begin{array}{r}-0.015^{* *} \\
(0.0045)\end{array}$ & \\
\hline $\begin{array}{l}\text { Fixed effects } \\
\mathrm{N}\end{array}$ & $\begin{array}{l}\text { Month } \\
26304\end{array}$ & $\begin{array}{l}\text { Month } \\
26304\end{array}$ & $\begin{array}{l}\text { Month } \\
26304\end{array}$ & $\begin{array}{l}\text { Week } \\
26304\end{array}$ & $\begin{array}{l}\text { Month } \\
26304\end{array}$ & $\begin{array}{l}\text { Month } \\
26304\end{array}$ & $\begin{array}{l}\text { Month } \\
26304\end{array}$ & $\begin{array}{l}\text { Week } \\
26304\end{array}$ \\
\hline
\end{tabular}

${ }^{*} \mathrm{p}<.10,{ }^{* *} \mathrm{p}<0.05,{ }^{* * *} \mathrm{p}<0.01$

Note: In columns (1)-(4) the dependent variable is nuclear capacity net of maintenance. Columns (5)-(8) present the corresponding results for failures. Hour-of-the-day fixed effects are included in all regressions. Standard errors are clustered by week. Variables are log transformed.

\section{Simulating output under different strategic behav- iors}

In this section I formulate a more comprehensive model to simulate optimal nuclear output given three behavioral assumptions: maximal collusion; Cournot competition; and a divested solution where aggregate nuclear profits are maximized, but no weight is given to other non-nuclear output. I also acknowledge that firms are forward contracted, limiting incentives to raise the day-ahead price. I simplify the model by letting owners decide on output once every week, consistent with the observation that more than 95 percent of the maintenance periods reported in the Urgent Market Messages database are at least one week long. This modeling choice is also consistent with the results in section 5.2 above, demonstrating that strategic incentives do not predict within-week variation in outages. Although it would be possible to allow for within-week variation in the simulation exercise, this would likely generate incentives to perform maintenance in much shorter intervals than what would be technically and economically viable.

Under Cournot competition, the majority owner chooses a level of output that maximizes the sum of its own profit from nuclear and other production. This means that Vattenfall takes the output decisions in Ringhals and Forsmark, while E.ON takes the output decisions in Oskarshamn. In the simulation for Vattenfall, Ringhals and Forsmark are ag- 
gregated to resemble one large plant, as the marginal cost of nuclear is constant. Fortum will remain a passive owner in all plants. Under maximal collusion, output decisions are taken to maximize aggregate profits of all three owners' nuclear and other output. Henceforth I will refer to this model simply as "collusion". Under the divested solution, output decisions are taken to maximize the profit on aggregate nuclear output only, while giving no weight to other output. Below, I formally describe the outline of each model.

Cournot competition. Nuclear output is determined as a best-response given the output of the nuclear plant(s) controlled by the competing firm. Further, the majority owner takes into account both other firms' passive ownership in the plant it controls, as well as its passive ownership in plants where it is a minority owner. Since all firms have already submitted supply functions tied to their whole fleet of plants (each firm submits one bid per price area), varying nuclear output has an effect on the output of non-nuclear plants through its effect on the price. After computing the best-response functions of each firm, the Cournot equilibrium for each week is found at the intersection of these functions.

I denote the profit of majority owner $i$ in hour $h$ of day $d$ by $\pi_{h d}^{i}$, and the output in the nuclear plant(s) controlled by majority owner $i$ by $q_{h d}^{i}$, with the associated capacity $\bar{q}^{i}$. The inverse residual demand function facing firm $i$ 's nuclear plant is $p_{h d}^{i}\left(q_{h d}^{i}\right)$, firm $i$ 's supply function net of nuclear output is $S_{h d}^{i}\left(p_{h d}^{i}\left(q_{h d}^{i}\right)\right)$, the constant marginal cost of nuclear is $f$, and the total cost of other production is $C_{h d}^{i}\left(p_{h d}^{i}\left(q_{h}^{i} d\right)\right)$. Further, the ownership share in firm $i$ 's own plant is denoted by $\eta_{i}^{i}$, and $i$ 's passive ownership shares in the plants controlled by firm $j \neq i$ are $\eta_{j}^{i}$. The price of the forward obligations is $p_{h d}^{c i}$, and the contract volume is $x_{h d}^{i}$. 
The objective function of firm $i$ is then:

$$
\begin{gathered}
\max _{q_{h d}^{i}} \pi_{h d}^{i}=\underbrace{p_{h d}^{i}\left(q_{h d}^{i}\right)\left[\eta_{i}^{i} q_{h d}^{i}+\sum_{j \neq i} \eta_{i}^{j} q_{h d}^{j}+S_{h d}^{i}\left(p_{h d}^{i}\left(q_{h d}^{i}\right)\right)\right]}_{\text {Spot market revenue }}-\underbrace{f\left[\eta_{i}^{i} q_{h d}^{i}+\sum_{j \neq i} \eta_{i}^{j} q_{h d}^{j}\right]-C_{h d}^{i}\left(p_{h d}^{i}\left(q_{w}^{i}\right)\right)}_{\text {Spot market cost }} \\
+\underbrace{\left[p_{h d}^{c i}-p_{h d}^{i}\left(q_{h d}^{i}\right)\right] x_{h d}^{i}}_{\text {Financial profit }}
\end{gathered}
$$

Subject to the constraints:

$$
\begin{gathered}
q_{h d}^{i} \leq \bar{q}_{w}^{i} \\
p_{h d}^{i}\left(q_{h d}^{i}\right) \leq 2000 E U R / M W h \\
q_{k}^{i}=q_{l}^{i} \forall k, l \in \mathbf{w}
\end{gathered}
$$

Where (6) is the capacity constraint. The next constraint (7) reflects the Nord Pool price cap of $2000 \mathrm{EUR} / \mathrm{MWh}$. If nuclear plants are pivotal, which sometimes occur, this constraint implies that it is never possible to raise prices above the cap by withholding more output. During the sample period, observed prices never reached the cap (the maximum recorded price was $225 \mathrm{EUR} / \mathrm{MWh}$ ). Last, constraint (8) states that nuclear output has to be the same for all hours belonging to the same week-of-sample $w$.

Differentiating (5) with respect to the decision variable $q_{h d}^{i}$, omitting time subscripts and rearranging yields:

$$
p^{i}=\frac{\overbrace{\eta_{i}^{i} f+\frac{\partial C^{i}\left(q^{i}\right)}{\partial q^{i}}}^{\text {Marginal cost }}+\overbrace{\left|\frac{\partial p^{i}\left(q^{i}\right)}{\partial q^{i}}\right|\left[\eta_{i}^{i} q^{i}+\sum_{j \neq i} \eta_{i}^{j} q^{j}+\frac{\partial S^{i}\left(q^{i}\right)}{\partial q^{i}}-x^{i}\right]}^{\text {Markup }}}{\eta_{i}^{i}+\frac{\partial S^{i}\left(q^{i}\right)}{\partial q^{i}}}
$$

Which gives the optimal equilibrium price of firm $i$ as a function of marginal costs and the price sensitivity of the inverse residual demand function, also taking into account the profit on non-nuclear output as well as the impact on financial revenues. As evident from (9), the optimal price is decreasing in the volume of forward contracts $x^{i}$. Further, the contract price $p_{h d}^{c i}$ has no impact on the optimal equilibrium spot price.

Collusion. Letting $\pi_{h d}^{\text {joint }}$ be the joint profit on the owners' total output, and $q_{h d}^{\text {nuc }}$ be aggregated nuclear output, the objective function under collusion becomes: 


$$
\begin{gathered}
\max _{q_{h d}^{\text {nuc }}} \pi_{h d}^{\text {joint }}=\underbrace{p_{h d}^{\text {joint }}\left(q_{h d}^{\text {nuc }}\right)\left[q_{h d}^{\text {nuc }}+S_{h d}^{\text {joint }}\left(p_{h d}^{\text {joint }}\left(q_{h d}^{\text {nuc }}\right)\right)\right]}_{\text {Spot market revenue }}-\underbrace{f q_{h d}^{\text {nuc }}-C_{h d}^{\text {joint }}\left(p_{h d}^{\text {joint }}\left(q_{h d}^{\text {nuc }}\right)\right)}_{\text {Spot market cost }} \\
+\underbrace{\left[p_{h d}^{\text {cjoint }}-p_{h d}^{\text {joint }}\left(q_{h d}^{\text {nuc }}\right)\right] x_{h d}^{\text {joint }}}_{\text {Financial profit }}
\end{gathered}
$$

Subject to the corresponding constraints as in the Cournot case above. Since the collusive model is a special case of the Cournot model where $n_{i}^{i}=1$ and $n_{i}^{j}=0$, omitting time subscripts, the first-order condition becomes:

$$
p^{\text {joint }}=\frac{\overbrace{f+\frac{\partial C^{\text {joint }}\left(q^{\text {nuc }}\right)}{\partial q^{\text {nuc }}}}^{\text {Marginal cost }}+\overbrace{\left|\frac{\partial p^{\text {joint }}\left(q^{\text {nuc }}\right)}{\partial q^{\text {nuc }}}\right|\left[q^{\text {nuc }}+\frac{\partial S^{\text {joint }}\left(q^{\text {nuc }}\right)}{\partial q^{\text {nuc }}}-x^{\text {joint }}\right]}^{\text {Markup }}]}{1+\frac{\partial S^{\text {joint }}\left(q^{\text {nuc }}\right)}{\partial q^{\text {nuc }}}}
$$

Divested solution. Letting $\pi^{n u c}$ be the profit on the nuclear plants alone, the corresponding objective function under the divested model becomes:

$$
\max _{q_{h d}^{n u c}} \pi_{h d}^{n u c}=\underbrace{p_{h d}^{n u c}\left(q_{h d}^{n u c}\right) q_{h d}^{n u c}}_{\text {Spot market revenue }}-\underbrace{f q_{h d}^{n u c}}_{\text {Spot market cost }}+\underbrace{\left[p_{h d}^{c n u c}-p_{h d}^{n u c}\left(q_{h d}^{n u c}\right)\right] x_{h d}^{n u c}}_{\text {Financial profit }}
$$

Subject to the same constraints as in the collusive model above. Since the divested model is a special case of the collusive model where $S^{\text {joint }}=0$, we get the following first-order condition:

$$
p^{n u c}=\underbrace{f}_{\text {Marginal cost }}+\underbrace{\left|\frac{\partial p^{n u c}\left(q^{n u c}\right)}{\partial q^{n u c}}\right|\left[q^{n u c}-x^{n u c}\right]}_{\text {Markup }}
$$

\subsection{A dynamic extension}

Solving for the optimal output trajectories under the different models highlights both differences in incentives to reduce the mean level of output, as well as incentives shaping the intertemporal allocation of output. However, the models are silent about the minimum level of maintenance needed for refueling and keeping the reactors in compliance with safety standards. For example, the divested model generates an optimal output path that implies close to full capacity utilization during extended periods. Evaluating which behavioral model fits data best is then challenging, as it relies on the researchers' ability to assess if necessary maintenance obligations could be fulfilled given each specific solution. 
Therefore, it is also of interest to solve the models while keeping the mean capacity factors at the observed levels, limiting the risk that maintenance obligations could not be fulfilled. One candidate solution would be to impose a constraint on the mean yearly capacity factors. However, solving such a model would be intractable, involving many degrees of freedom. Further, maintenance could then be allocated completely freely within each year without any further considerations about the technical feasibility of the specific output trajectories. For example, it may not be technically feasible to allocate all maintenance to the summer season, even if such an allocation would be optimal given the model assumptions.

Instead, I consider a more tractable constraint by only allowing for reallocation of output across consecutive weeks. That is, I divide the sample into periods of two weeks each, and impose the constraint that the sum of output across consecutive weeks should equal the sum of the observed output during those weeks. Letting $\mathbf{z}$ be the set of all integers up to 78 (there are 156 weeks in the sample), the dynamic constraint becomes:

$$
\sum_{j=w}^{j+1} q_{w}^{i}=\sum_{j=w}^{j+1} q_{w}^{i(o b s)} \forall w=2 z+1
$$

Which creates a set of 78 periods with 2 weeks in each period. In contrast to a more flexible approach with higher degrees of freedom, the problem is straightforward to solve since the output choice in any given week $w+1$ is the residual from the output choice in week $w$. Omitting the capacity constraint, the general optimization problem for week $w$ becomes:

$$
\max _{q_{w}^{i}} \sum_{j=w}^{j+1} \pi_{w}^{i} \forall w=2 z+1
$$

Subject to (14), which yields the Lagrangian:

$$
\mathcal{L}_{w}^{i}=\sum_{j=w}^{j+1} \pi_{w}^{i}\left(q_{w}^{i}\right)-\lambda\left(\sum_{j=w}^{j+1} q_{w}^{i}-\sum_{j=w}^{j+1} q_{w}^{i(o b s)}\right)
$$

The first-order condition can then be expressed as

$$
\frac{\partial \pi_{w}^{i}\left(q_{w}^{i}\right)}{\partial q_{w}^{i}}=\frac{\partial \pi_{w+1}^{i}\left(q_{w+1}\right)}{\partial q_{w+1}}
$$

Which states that marginal profits will be equalized across consecutive weeks. Naturally, if the marginal profit would be higher in week $w$ than in week $w+1$, it would be optimal to shift more output to week $w$ and thereby increase total profits. The optimization problem is very similar to that of a hydro power plant with a reservoir, as outlined by Førsund (2006), since expanding output in one period means that there is less water in the reservoir to use during the following period. 


\subsection{Fitting data to the model}

I estimate firm $i$ 's bid from other production according to $S_{h d}^{i}\left(p_{h d}^{i}\right)=\lambda^{i}\left[S_{h d}^{\text {system }}\left(p_{h d}\right)-\right.$ $q_{h d}^{n u c}$, where the scalar $\lambda^{i}$ is firm $i$ 's market share on non-nuclear output discussed in section 3.1, compiled by the Nordic Energy Regulators (Nordreg, 2011, 2012, 2013). Since the divested model is a special case of the collusive model where $\lambda^{i}=0$ for all firms, I also conduct robustness tests by symmetrically scaling each $\lambda^{i}$ reflecting a combined market share of 0 to 80 percent.

In the baseline model I assume that all non-nuclear output are bid into the market at marginal cost. Thus, firm i's cost function of non-nuclear output is $C_{h d}^{i}\left(p_{h d}^{i}\right)=$ $\int_{p_{h d}^{m i n}}^{p_{h d}^{i}} S_{h d}^{i}(x) d x$. The assumption of competitive bidding is certainly a simplification, and in the robustness section I solve the model for a range of parameter values reflecting a markup of 0 to 30 percent.

Using the estimated volume of yearly forward sales from the financial statements, I need to allocate contracts within each year. For simplicity, I assume that forward obligations are load following, i.e., that the forward obligations during a certain week are proportional to the forecasted demand during that week. When solving for the divested solution, I adjust forward volumes to match the yearly hedging ratio with respect to nuclear output only (otherwise firms would be heavily over-contracted). Figure A10 depicts the estimated forward sales and observed output throughout the sample period under the divested model. As seen in the figure, observed nuclear output follows estimated forward sales well, and observed output exceeds the estimated contracting volume in 97 percent of all weeks. In the robustness section I also simulate output for a range of parameter values reflecting hedging ratios down to zero percent.

The solution technique is described in Appendix B.

\subsection{Results}

Figure A11, A12, and A13 depict monthly aggregated simulated output trajectories given each behavioral assumption under the static model, as well as the observed output trajectory. Simulated output follows observed output well, and the collusive solution generates the strongest incentives to contract output, followed by the Cournot and divested models, respectively. Figure A14, A15, and A16 instead depict the corresponding weekly output trajectories, revealing that the simulation generates incentives to vary output in shorter intervals than what is observed in the data. This is not surprising, since the model does not incorporate any technical constraints on the feasibility of varying output swiftly. Adding such constraints would require a substantially more complex solution technique.

Summary statistics of market outcomes are presented in Table 6. Prices and profits are computed as percentages of the corresponding figure given observed nuclear output. Profits are the sum of the profits on all three nuclear owners' total generation, including non-nuclear. 
Table 6: Descriptive statistics of simulated market outcomes

\begin{tabular}{lcc}
\hline Model & Static & Dynamic \\
\hline Collusion & & \\
Capacity factor & 76 & 76 \\
Equilibrium price & 118 & 107 \\
Profit & 128 & 109 \\
\hline Cournot & & \\
Capacity factor & 89 & 76 \\
Equilibrium price & 105 & 106 \\
Profit & 127 & 108 \\
\hline Divested & & \\
Capacity factor & 94 & 76 \\
Equilibrium price & 97 & 105 \\
Profit & 119 & 107 \\
\hline
\end{tabular}

Note: Capacity factors are expressed in percentages. Prices and profits are computed as percentages of the corresponding figure given observed nuclear output. Profits are the sum of the profits on all nuclear owners' total generation, including non-nuclear.

Static model. Under the static specification (left column in Table 6), the collusive model generates stronger incentives to withhold capacity than the other models, with a mean capacity factor of 76 percent, compared to 89 for the Cournot model and 94 for the divested solution. Notably, the collusive model matches the observed mean capacity factor of 76 percent exactly.

The volume-weighted average price under the collusive model is 118 percent of the observed price. Under the Cournot model, the corresponding figure is 105 percent, and under the divested model it is instead 97 percent. An important reason for the relatively high mean price under the collusive model is a few price spikes during the winter. When comparing median prices, the collusive price is instead 110 percent of the observed price.

As expected, profits are higher under the collusive model than the other models, at 128 percent of the observed figure, compared to 127 percent for the Cournot model and 119 percent for the divested solution. To enable comparisons across models, profits are computed as the sum of profits including non-nuclear output for all owners. Since profits also include profits on the financial market, figures are based on the simplified assumption that forward prices equal the corresponding simulated spot prices, i.e., there is no arbitrage.

In terms of allocative efficiency, the welfare effects of contracting nuclear output are in principle negligible due to a highly inelastic short term demand. However, there are likely negative effects on productive efficiency. First, since the marginal cost of nuclear is lower than for other thermal plants, system production costs increase when these plants expand output as a response to the contraction in nuclear output. Second, shifting nuclear maintenance towards periods with a relatively price sensitive residual demand (while 
keeping total nuclear output constant) leads to increased system production costs when the residual demand function is convex (due to Jensen's inequality). However, since I do not observe generation unit level output for the other thermal plants, it is not possible to appropriately quantify these inefficiencies using the current modeling framework. Furthermore, thermal units only account for a relatively small fraction of total production, since the market is dominated by hydroelectric units which have little or no direct cost of production. Within the current modeling framework, it is not possible to appropriately quantify the extent to which these hydroelectric units alone are able to compensate for the variation in nuclear output.

Dynamic model. When including the dynamic constraint in eq. (14), results are qualitatively similar to the static specification (right column in Table 6), although differences are much less pronounced since the only way to generate changes in market outcomes is by shifting output across consecutive weeks.

The price under collusion is still higher than under the other models, but only at 109 percent of the observed price compared to 108 and 107 percent for the Cournot and divested models respectively. Also, profits are only marginally higher under the collusive model compared to the other models.

\subsection{Model selection}

To examine model fit, I regress observed output on simulated output under each model according to:

$$
q_{w}^{o b s}=\alpha+\gamma_{0} q_{w}^{s i m}+\varepsilon_{w}
$$

Where $q_{w}^{\text {obs }}$ is the observed aggregate weekly output of all plants, and $q_{w}^{\text {sim }}$ is the corresponding simulated output with its associated coefficient $\gamma_{0}$, and $\varepsilon_{w}$ is the error term. A perfect fit implies that $\gamma_{0}=1$ and $R^{2}=1$. When estimating the dynamic specification, I begin by computing the mean output during each consecutive two-week period. Due to the dynamic constraint, this figure is identical for both observed and simulated output. I then subtract this mean from $q_{w}^{o b s}$ and $q_{w}^{s i m}$, and regress the residuals. Otherwise, adjusted $R^{2}$ would become very large. In the static specifications, standard errors are clustered by month, and in the dynamic specifications clustering is by each two-week period.

Results are reported in Table 7, where each column presents the results from a separate regression. 
Table 7: Dependent variable: Observed weekly output

\begin{tabular}{lcccccccc}
\hline & \multicolumn{3}{c}{ Static } & & \multicolumn{3}{c}{ Dynamic } \\
\cline { 2 - 3 } & Collusion & Divested & Cournot & & Collusion & Divested & Cournot \\
\hline Simulated output & $0.26^{* * *}$ & $0.59^{* * *}$ & $0.24^{* *}$ & & $0.21^{* * *}$ & $0.22^{* * *}$ & $0.074^{* * *}$ \\
& $(0.058)$ & $(0.16)$ & $(0.10)$ & & $(0.036)$ & $(0.043)$ & $(0.022)$ \\
\hline Cluster level & Month & Month & Month & Two weeks & Two weeks & Two weeks \\
$R^{2}$ & 0.19 & 0.16 & 0.072 & & 0.18 & & 0.15 & 0.070 \\
$\mathrm{~N}$ & 156 & 156 & 156 & & 156 & & 156 & 156 \\
\hline
\end{tabular}

$* \mathrm{p}<.10,{ }^{* *} \mathrm{p}<0.05, * * * \mathrm{p}<0.01$

Note: The dependent variable is observed aggregate nuclear output. Each column presents the results from a separate regression. Standard errors in parentheses.

Results from the static model are presented in the first three columns. All estimates yield positive and statistically significant estimates of $\hat{\gamma}_{0}$. Using $R^{2}$ as goodness of fit measure, the collusive model fits data best with an adjusted $R^{2}$ of 0.19 . The corresponding figures for the divested and Cournot models are 0.16 and 0.072 respectively. The last three columns present the results given the dynamic specification. Also here, all estimates yield positive and highly significant estimates of $\hat{\gamma}_{0}$, and the collusive model matches data best, followed by the divested and the Cournot models respectively.

A relevant question is then whether the collusive model alone can explain the variation in observed output, or if firms exhibit behavior that can partly be explained by the other models. To test this, I perform a J-test of non-nested hypotheses following Davidson and MacKinnon (1981). The same procedure has also been used by e.g. Bushnell et al. (2008), although their main variable of interest is simulated prices and not quantities. To perform the J-test, I consider the following comprehensive model:

$$
q_{w}^{o b s}=\left(1-\theta^{\text {alt }}\right) \beta_{0} q_{w}^{\text {coll }}+\theta^{\text {alt }} \beta_{1} q_{w}^{\text {alt }}+\varepsilon_{w}
$$

Where $q_{w}^{a l t}$ is the simulated output profile of the alternative hypothesis, i.e., Cournot competition or the divested solution, and the mixing parameter $\theta^{\text {alt }}$ determines the relative weight on the alternative model for predicting firm conduct. When no a priori information is available, the mixing parameter is not identifiable in the comprehensive model. The Jtest works around this by replacing $\beta_{1} q_{w}^{\text {alt }}$ with the fitted values from a regression of $q_{w}^{\text {obs }}$ on $q_{w}^{a l t}$, and then testing the mixing parameter for statistical significance, i.e., $H_{0}: \theta^{\text {alt }}=0$. If the null hypothesis is not rejected, it is also necessary to "reverse" the model and test $H_{0}: \theta^{\text {coll }}=0$ to confirm that this new null hypothesis is indeed rejected.

Table 8 displays the p-values for different tests under both the static and dynamic specification. As seen in Table $8, H_{0}: \theta^{\text {coll }}=\left(1-\theta^{\text {alt }}\right)=0$ is rejected in all cases. The interpretation is that there is some variation in the data that can only be explained by the collusive model. Further, $H_{0}: \theta^{\text {alt }}=0$ is rejected for both competing models in the dynamic case. However, in the static case it is not rejected for the divested model. The interpretation is that explanatory power is improved when also including information 
Table 8: J-test of non-nested hypotheses

\begin{tabular}{lcc}
\hline Alternative model & $H_{0}: \theta^{\text {alt }}=0$ & $H_{0}: \theta^{\text {coll }}=0$ \\
\hline Divested & & \\
Static & 0.01 & 0.00 \\
Dynamic & 0.35 & 0.04 \\
Cournot & & \\
Static & 0.44 & 0.00 \\
Dynamic & 0.80 & 0.00 \\
\hline
\end{tabular}

Note: The table displays p-values for the null hypothesis in several J-tests of non-nested hypotheses.

from this model.

Hence, it appears that firms are not always able to coordinate on the collusive equilibrium. There are several reason why firms may not achieve perfect coordination. In the literature, the most discussed one is due to the folk theorem, stating that any quantity between Cournot competition and joint profit maximization is compatible with some Nash equilibrium in an infinitely repeated game. However, in the current setup a more likely reason is regulatory threat. As discussed in the introduction, nuclear owners are obliged not to perform maintenance during the winter season (November-March) unless it can be motivated for safety reasons: Removing all nuclear output generates prices at least twice as high as the observed figures during one third of all hours during the winter seasons. However, if extensive maintenance would be performed despite the regulatory obligation to refrain from doing so, the probability of the introduction of a severely stricter regulatory framework would increase drastically.

To test if regulatory threat is consistent with the observed variation in nuclear output, I consider a hybrid case by considering the indicator winter $=1$ for all observations November-March and letting

$$
q_{w}^{\text {hybrid }}= \begin{cases}q_{w}^{\text {divest }} & \text { if winter }=1 \\ q_{w}^{\text {coll }} & \text { otherwise }\end{cases}
$$

Regressing observed output on $q_{w}^{\text {hybrid }}$ now yields an $R^{2}$ of 0.29 , a figure that is about 50 percent higher than when considering the collusive model alone, consistent with the hypothesis that the threat of regulatory intervention has a pro-competitive effect during the winter season. If constructing the inverse of $q_{w}^{\text {hybrid }}$ by instead inserting values from the collusive model during the summer and vice versa, $R^{2}$ instead becomes very low, at 0.05. Further, when regressing observed output on $q_{w}^{\text {hybrid }}$ under the dynamic specification, $R^{2}$ also becomes greater than under the collusive model at about 0.2 , even if the relative increase in $R^{2}$ is now less pronounced. 


\subsection{Robustness}

Solving for the competitive solution. Since high volumes of forward contracts generate incentives to behave similar to a competitive firm, I simulate output under the assumption that nuclear owners behave competitively. In the static case, this means that nuclear output expands until the price equals the marginal fuel cost of $5 \mathrm{EUR} / \mathrm{MWh}$. Applying this assumption to data generates a mean capacity factor of 98 percent, i.e., the capacity constraint binds almost every week. The mean price is then $34 \mathrm{EUR} / \mathrm{MWh}$, or correspondingly 87 percent of the observed price. Since the variation in simulated output is then trivial, regressing observed output on simulated output does not provide any useful information. Under the dynamic specification, a competitive firm shifts output towards the week with the highest price until prices between consecutive weeks are equalized, or when the capacity constraint binds. Applying this assumption to data generates a price that is 2 percent lower than the observed price. Regressing observed output on simulated output is now informative of model fit, and generates an $R^{2}$ of 0.1 , which is lower than the corresponding figures for both the collusive and divested models. Further, the J-test rejects the competitive solution in favor of the hybrid model. ${ }^{9}$

Next, I test for parameter sensitivity in several dimensions. For each associated parameter value, I solve for optimal output and regress observed output on simulated optimal output according to eq. (17). I then plot $R^{2}$ as a function of the corresponding parameter. Results for the static and dynamic specifications are depicted in Figure A18 and A19 respectively. In all robustness tests, the hybrid model performs best for the whole range of parameter values. However, the sensitivity in $R^{2}$ differs depending on the type of parameter tested.

Markup on non-nuclear output. In the first robustness test, I scale down the cost function of non-nuclear output, $C_{h d}^{i}\left(p_{h d}^{i}\right)$, by a factor reflecting a markup between 0 to 30 percent. The impact on $R^{2}$ is marginal throughout all specifications.

Nuclear marginal cost. I let the nuclear marginal cost $f$ vary between 0 to 10 EUR/MWh. $R^{2}$ is slightly increasing in the marginal cost within all models under the static case, while it is invariant in the dynamic case. The latter result is mechanical: Since aggregate nuclear output is given exogenously for each two-week period, varying $f$ cannot affect the optimal intertemporal allocation of output.

Hedging ratio. I multiply the reported hedging ratio of each firm by a factor ranging between zero to unity. $R^{2}$ is now comparatively sensitive to the parameter value chosen, although the hybrid model still performs best throughout. It is notable that the best fit is achieved when forward contracts are assumed to be non-existent, and that this result is driven mainly by the collusive model. Although it is beyond the scope of this paper to comprehensively analyze optimal behavior under forward contracts, one potential explanation is given by Liski and Montero (2006). They note that the standard procompetitive result by Allaz and Vila (1993) relies on a static model where the spot market is cleared only once. In real markets, a repeated game setting is more appropriate, with

\footnotetext{
${ }^{9}$ Testing the hybrid model against the competitive solution yields a probability of 0.01 that $H_{0}$ : $\theta^{\text {hybrid }}=0$, and a probability of 0.37 that $H_{0}: \theta^{\text {comp }}=0$.
} 
multiple rounds of spot market clearings. Within such a setting, they show that firms may maintain short positions in the forward market while still achieving perfect collusion on the spot market, and hence also collusive profits (since the forward price equals the expected spot price). Forward contracting may even expand the range of discount factors for which maximal collusion can be sustained.

Market share on non-nuclear output. I symmetrically scale each $\lambda^{i}$ to reflect a combined market share on non-nuclear output between 0 and 80 percent (the observed figure is 26 percent). $R^{2}$ is now comparatively sensitive, although the hybrid model still performs best throughout. Notably, the worst fit is achieved by letting $\lambda^{i}=0$ for all $i$ (i.e., when both the collusive and hybrid models converge to the divested model), demonstrating that owners also consider profits on other output when optimizing nuclear output. However, $R^{2}$ is increasing up until a market share of about 50 percent, i.e., a figure that is about twice as large as the observed figure. The incentives generated by assuming a high non-nuclear market share are very similar to the incentives generated by assuming a low hedging ratio, since in both cases price variations on the day-ahead market are factored into the firms' profit functions to a greater extent. In light of the previous results demonstrating that $R^{2}$ is decreasing in hedging ratio, it is therefore not surprising that $R^{2}$ is also increasing in the market share on non-nuclear output.

\section{Conclusion}

I study the anticompetitive effects of joint ownership of Swedish nuclear plants, finding indications of collusive behavior by means of capacity reductions. However, I find that behavior is relatively more competitive during the winter period, when demand peaks and regulatory oversight is stricter.

From a regulatory perspective it is of special interest that market power is exercised by withdrawing capacity from the market. This means that the regulator cannot effectively monitor firms by estimating the markup on existing bids. Since maintenance schedules are available to other market participants through the Urgent Market Messages database, messages may be used to share information about schemes on how to exercise market power. Further research could investigate if strategic incentives shape the way that firms reveal new information to the market, and examine whether the mandatory publication of maintenance schedules has resulted in a more competitive outcome (which is the regulator's intention), or if it has facilitated anticompetitive coordination. Since the EU is currently implementing regulations to increase the transparency in electricity markets in which maintenance scheduling is an essential element (ACER, 2015), the findings in the present paper are highly relevant from a policy perspective. In most other electricity markets, firms are not completely free to choose the timing of maintenance themselves, but are obliged to reschedule if the transmission system operator finds that too much capacity will be offline at the same time. The findings in the present paper suggest that such an arrangement could lead to a more efficient allocation of maintenance also in the Nordic region.

Another way to promote competition in the day-ahead market may be to oblige firms 
to sell a larger share of their output (both nuclear and non-nuclear) through fixed-price forward contracts. Such regulatory interventions have previously been used in several other European countries, for example France, Belgium, Spain, Denmark, Germany, and Portugal (Ausubel and Cramton, 2010).

Lastly, it is important to emphasize that the low capacity factors of the Swedish nuclear plants may at least in part be explained by the political decision in 1980 (by referendum) to gradually phase out nuclear. This decision may have incentivized owners to refrain from large-scale investments that could have mitigated the need for frequent maintenance disruptions. Still, the current analysis provides empirical evidence that the foregone revenues due to the capacity reductions have presumably been offset by an increase in revenues on the owners' non-nuclear output. 


\section{References}

ACER, "Regulation on Wholesale Energy Market Integrity and Transparency," https: //www.europex.org/eu-legislation/energy-market-integrity-remit/ (accessed November 2, 2019), 2015.

Allaz, Blaise and Jean-Luc Vila, "Cournot Competition, Forward Markets and Efficiency," Journal of Economic Theory, 1993, 59 (1), 1-16.

Alley, Wilson A., "Partial Ownership Arrangements and Collusion in the Automobile Industry," The Journal of Industrial Economics, 1997, 45 (2), 191-205.

Amundsen, Eirik S. and Lars Bergman, "Will Cross-Ownership Re-Establish Market Power in the Nordic Power Market?," The Energy Journal, 2002, 0 (Number 2), 73-95.

Ausubel, Lawrence M. and Peter Cramton, "Virtual power plant auctions," Utilities Policy, December 2010, 18 (4), 201-208.

Azar, José, Martin C. Schmalz, and Isabel Tecu, "Anticompetitive effects of common ownership," Journal of Finance, 2018, 73 (4).

_ , Sahil Raina, and Martin C Schmalz, "Ultimate ownership and bank competition," SSRN Working Paper 2710252, 2016.

Borenstein, Severin, James B. Bushnell, and Frank A. Wolak, "Measuring Market Inefficiencies in California's Restructured Wholesale Electricity Market," American Economic Review, December 2002, 92 (5), 1376-1405.

Bresnahan, Timothy F., "The oligopoly solution concept is identified," Economics Letters, 1982, 10 (1-2), 87-92.

Bushnell, James B., Erin T. Mansur, and Celeste Saravia, "Vertical Arrangements, Market Structure, and Competition: An Analysis of Restructured US Electricity Markets," American Economic Review, March 2008, 98 (1), 237-66.

Corts, Kenneth S., "Conduct parameters and the measurement of market power," Journal of Econometrics, 1999, 88 (2), 227 - 250.

Damsgaard, Niklas, "Market Power in the Nordic Power Market," Working Paper Series 2007-003, Econ Pöyry 2007.

Davidson, Russell and James G MacKinnon, "Several Tests for Model Specification in the Presence of Alternative Hypotheses," Econometrica, May 1981, 49 (3), 781-93.

Davis, Lucas and Catherine Wolfram, "Deregulation, Consolidation, and Efficiency: Evidence from US Nuclear Power," American Economic Journal: Applied Economics, 2012, 4 (4), 194-225.

Dietzenbacher, Erik, Bert Smid, and Bjorn Volkerink, "Horizontal integration in the Dutch financial sector," International Journal of Industrial Organization, December 2000, 18 (8), 1223-1242.

Energy Markets Inspectorate, "Ägarstrukturen på elmarknaden," Report EI R2012:21, Energy Market Inspectorate 2006.

_ , "Övervakning och transparens på elmarknaden," Report EI R2010:21, Energy Market Inspectorate 2010. 
ENTSO-E, Commission Regulation (EU) 2017/1485; System Operation Guide Line (SOGL), 2017.

E.ON, "Presentation on Annual reports 2011-2013," https://www.eon.com/en/ investor-relations/presentations.html (accessed November 3, 2019), 2014.

Fogelberg, Sara and Ewa Lazarczyk, "Strategic Withholding through Production Failures," Working Paper Series 1015, Research Institute of Industrial Economics March 2014.

Forsmark, Annual reports 2011, 2012, and 2013, Forsmark Kraftgrupp AB 2014.

Førsund, Finn, "The Anatomy of Market Power in Electricity Markets with Hydropower as Dominating Technology," ICER Working Papers, ICER - International Centre for Economic Research 2006.

Fortum, Financial statements for 2010-2012, 2013.

Fridolfsson, Sven-Olof and Thomas P. Tangerås, "Nuclear Capacity Auctions," The Energy Journal, 2015, 0 (Number 3).

Glazer, Amihai and Henry McMillan, "Pricing by the Firm Under Regulatory Threat," The Quarterly Journal of Economics, 1992, $10^{77}$ (3), 1089-1099.

Green, Edward J, "Noncooperative price taking in large dynamic markets," Journal of Economic Theory, 1980, 22 (2), 155 - 182.

Green, Richard J and David M Newbery, "Competition in the British Electricity Spot Market," Journal of Political Economy, October 1992, 100 (5), 929-53.

Hendricks, Kenneth and Robert H. Porter, "Joint Bidding in Federal OCS Auctions," The American Economic Review, 1992, 82 (2), 506-511.

Hjalmarsson, Erik, "Nord Pool: A Power Market Without Market Power," Working Papers in Economics 28, University of Gothenburg, Department of Economics 2000.

IAEA, "PRIS database," https://www.iaea.org/pris/ (accessed November 3 2019), 2015.

Kauppi, Olli and Matti Liski, "An Empirical Model of Imperfect Dynamic Competition and Application to Hydroelectricity Storage," Working Papers, Massachusetts Institute of Technology, Center for Energy and Environmental Policy Research 2008.

Kim, Dae-Wook and Christopher R. Knittel, "Biases in Static Oligopoly Models? Evidence from the California Electricity Market," Journal of Industrial Economics, December 2006, 54 (4), 451-470.

Liski, Matti and Juan-Pablo Montero, "Forward trading and collusion in oligopoly," Journal of Economic Theory, November 2006, 131 (1), 212-230.

Lundin, Erik and Thomas Tangerås, "Cournot Competition in Wholesale Electricity Markets: The Nordic Power Exchange, Nord Pool," Journal of Industrial Economics, October 2019, (Forthcoming).

Malueg, David A., "Collusive behavior and partial ownership of rivals," International Journal of Industrial Organization, March 1992, 10 (1), 27-34.

Mauritzen, Johannes and Thomas Tangerås, "Real-time versus day-ahead market power in a hydro-based electricity market," Journal of Industrial Economics, December 2018, 66 (4), 904-941. 
McRae, Shaun D. and Frank A. Wolak, "How do firms exercise unilateral market power? Empirical evidence from a bid-based wholesale electricity market," in Eric Brousseau and Jean-Michel Glachant, eds., The Manufacturing of Markets, Cambridge University Press, 2014, pp. 390-420. Cambridge Books Online.

Nordic Competition Authorities, "Capacity for Competition: Investing for an Efficient Capacity for Competition: Investing for an Efficient Capacity for Competition: Investing for an Efficient Nordic Electricity Market," Report 1:2007, Nordic Competition Authorities 2007.

Nordpool, "FTP server product details," https://www.nordpoolgroup. com/globalassets/download-center/power-data-services/ outline-nord-pool-ftp-server.pdf (accessed November 3, 2019), 2019.

Nordreg, "Nordic Market Report," Report 3:2011, Nordic Energy Regulators 2011.

_ , "Nordic Market Report," Report 3:2012, Nordic Energy Regulators 2012.

_ , "Nordic Market Report," Report 6:2013, Nordic Energy Regulators 2013.

OKG AB, Annual reports 2011, 2012, and 2013, OKG AB 2014.

Parker, Philip M. and Lars-Hendrik Röller, "Collusive Conduct in Duopolies: Multimarket Contact and Cross-Ownership in the Mobile Telephone Industry," RAND Journal of Economics, 1997, 28 (2), 304-322.

Pollitt, Michael G, "Ownership and Efficiency in Nuclear Power Production," Oxford Economic Papers, April 1996, 48 (2), 342-60.

Radio Sweden, "Interview with production planner at Vattenfall," http: //sverigesradio.se/sida/artikel. aspx?programid=83\&artikel=870163 (accessed November 3 2019), 2006.

Reynolds, Robert J. and Bruce R. Snapp, "The competitive effects of partial equity interests and joint ventures," International Journal of Industrial Organization, 1986, 4 (2), 141-153.

Ringhals, Annual reports 2011, 2012, and 2013, Ringhals AB 2014.

Schmalz, Martin C, "Common Ownership Concentration and Corporate Conduct," Annual Review of Financial Economics, December 2018, 10.

SMHI, "FTP server product details," https://www.smhi.se/klimatdata/ utforskaren-oppna-data/ (accessed November 3 2019), 2016.

Statistics Finland, "Monthly nuclear production 1990-2013," https://pxhopea2.stat. fi/sahkoiset_julkaisut/energia2018/html/ruot0000.htm (accessed November 3 2019), 2015.

Statistics Sweden, "Monthly nuclear production 1974-2013," http://www . statistikdatabasen.scb.se/pxweb/en/ssd/START__EN__EN0108/EltillfM/

?rxid=1d169fb6-7387-45b1-bc62-dd4bd58a5d35 (accessed November 3 2019), 2015.

Steen, Frode and Lars Sørgard, "Semicollusion in the Norwegian cement market," European Economic Review, October 1999, 43 (9), 1775-1796.

SvD, "High demand for nuclear specialists," https://www.svd.se/ sug-efter-karnkraftsspecialister (accessed November 3 2019), 2009. 
SvK, Interview with Pontus de Maré, COO at SvK, 2019.

Swedish Competition Authorities, "Bryt upp samägandet inom kärnkraften," http://www.konkurrensverket.se/globalassets/aktuellt/nyheter/ 2008pm-- - bryt-upp-samagandet-inom-karnkraften-dnr-5002008-49646kb .pdf (accessed November 3 2019), 2009.

Swedish Radiation Safety Authority, "Nuclear power plants in Sweden," http://www.stralsakerhetsmyndigheten.se/start/Karnkraft/ Anlaggningar-i-Sverige/ (accessed November 3 2019), 2014.

Tirole, Jean, The Theory of Industrial Organization, Vol. 1 of MIT Press Books, The MIT Press, January 1988.

Vattenfall, Financial statements 2010-2013, 2013.

Wolak, Frank, "An Empirical Analysis of the Impact of Hedge Contracts on Bidding Behavior in a Competitive Electricity Market," International Economic Journal, 2000, $14(2), 1-39$.

Wolak, Frank A., "Measuring Unilateral Market Power in Wholesale Electricity Markets: The California Market, 1998-2000," American Economic Review, 2003, 93 (2), 425-430.

- and Robert H. Patrick, "The Impact of Market Rules and Market Structure on the Price Determination Process in the England and Wales Electricity Market," Working Paper 8248, National Bureau of Economic Research April 2001.

Wolfram, Catherine D., "Measuring Duopoly Power in the British Electricity Spot Market," American Economic Review, 1999, 89 (4), 805-826. 
Appendix A

Figure A1: Swedish nuclear output 1990-2014

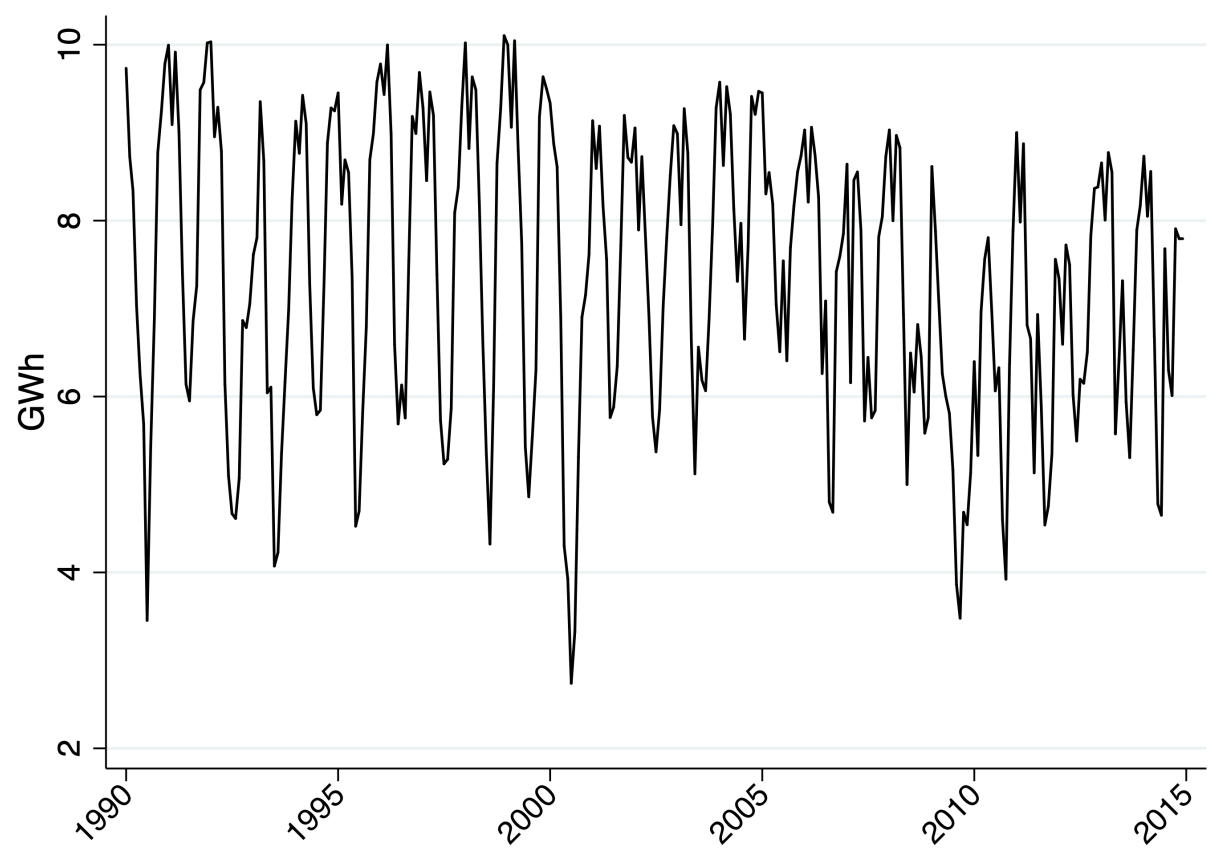

Note: Swedish nuclear output 1990-2014. Mean hourly output each month-ofsample. 
Figure A2: Finnish nuclear output 1990-2014

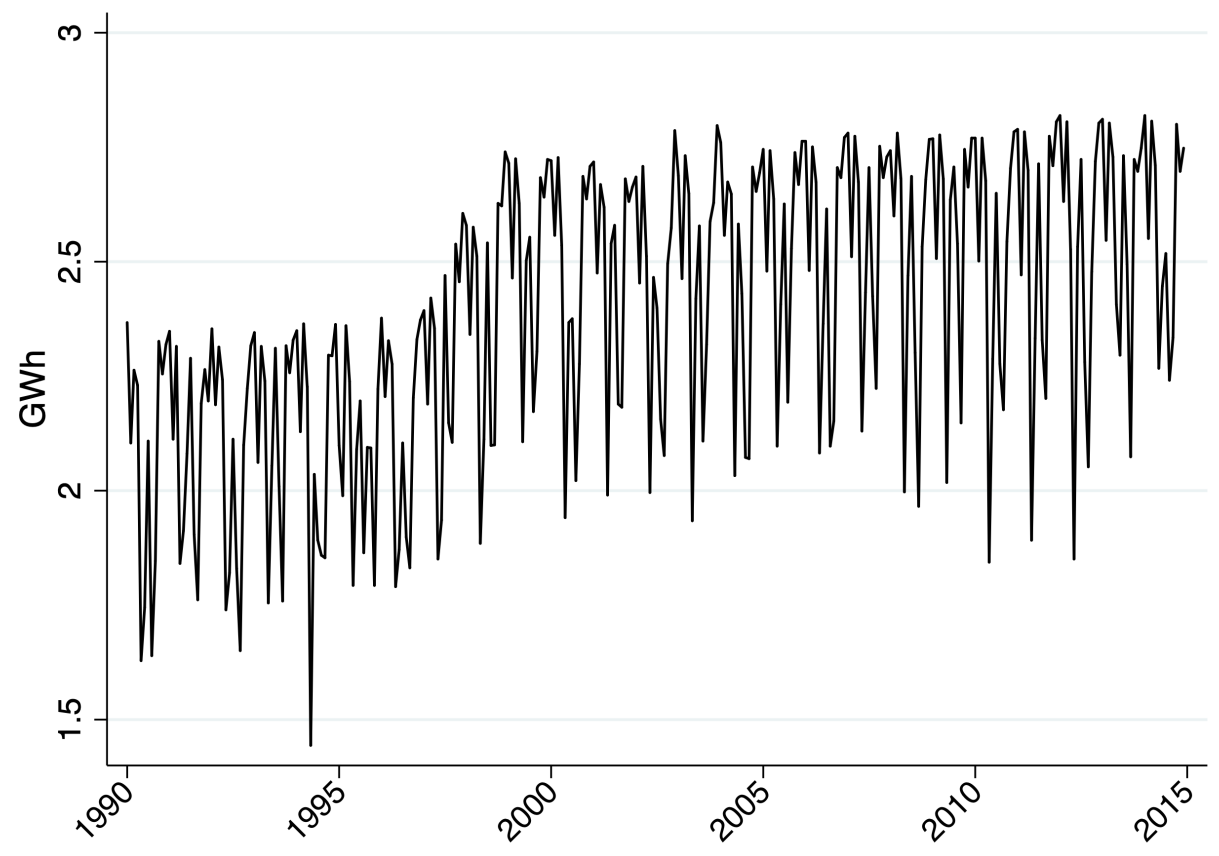

Note: Finnish nuclear output 1990-2014. Mean hourly output each month-of-sample.

Figure A3: Price zones in the Nordic electricity market

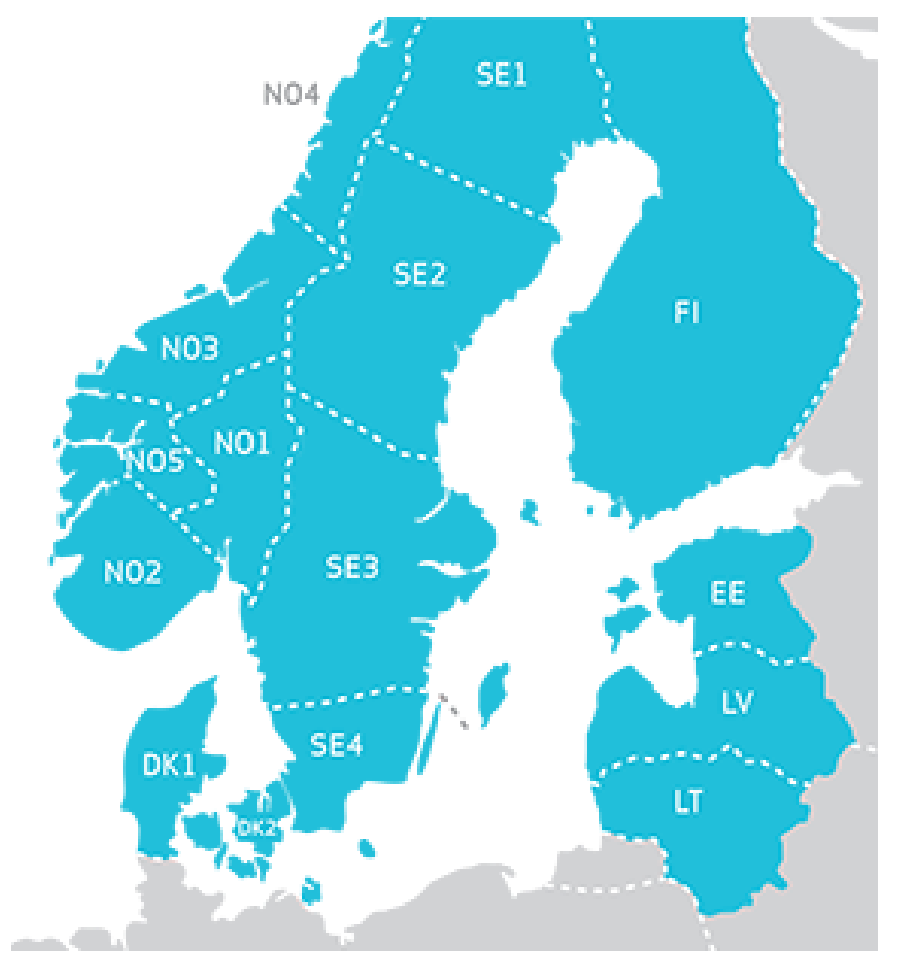

Note: Price zones in the Nordic electricity market. All Swedish nuclear plats are located in zone "SE3". 
Figure A4: Example of an Urgent Market Message

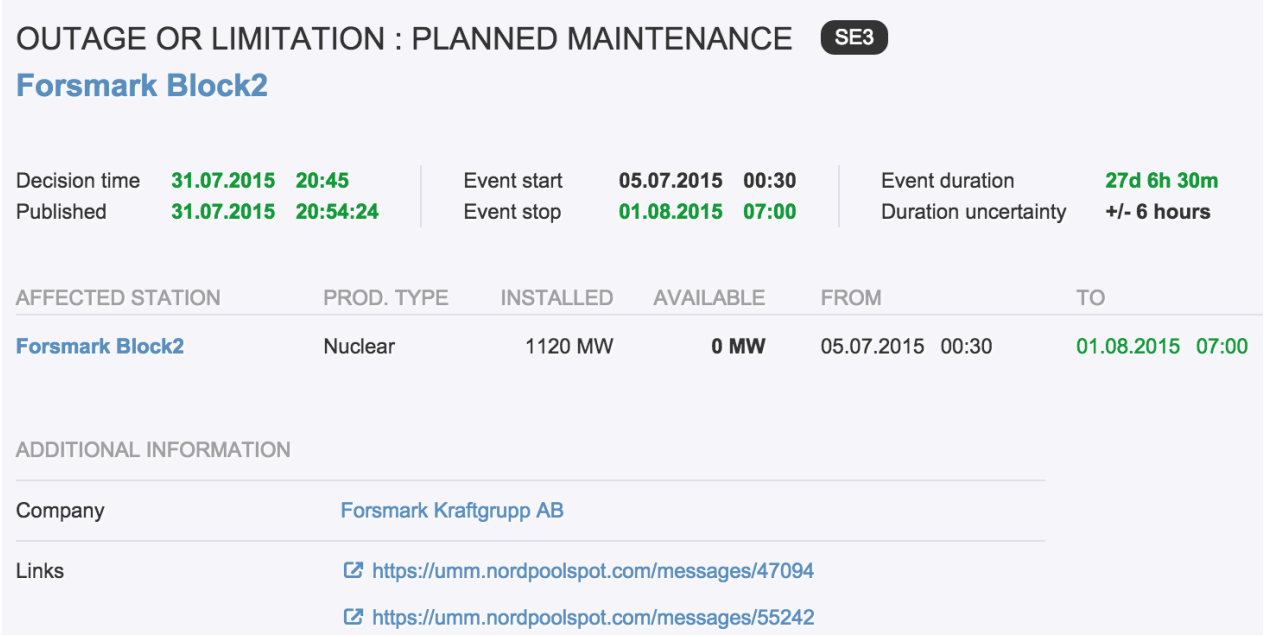

Note: An example of an Urgent Market Message regarding planned maintenance in reactor 2 in Forsmark.

Figure A5: Full capacity utilization net of outages reported as maintenance

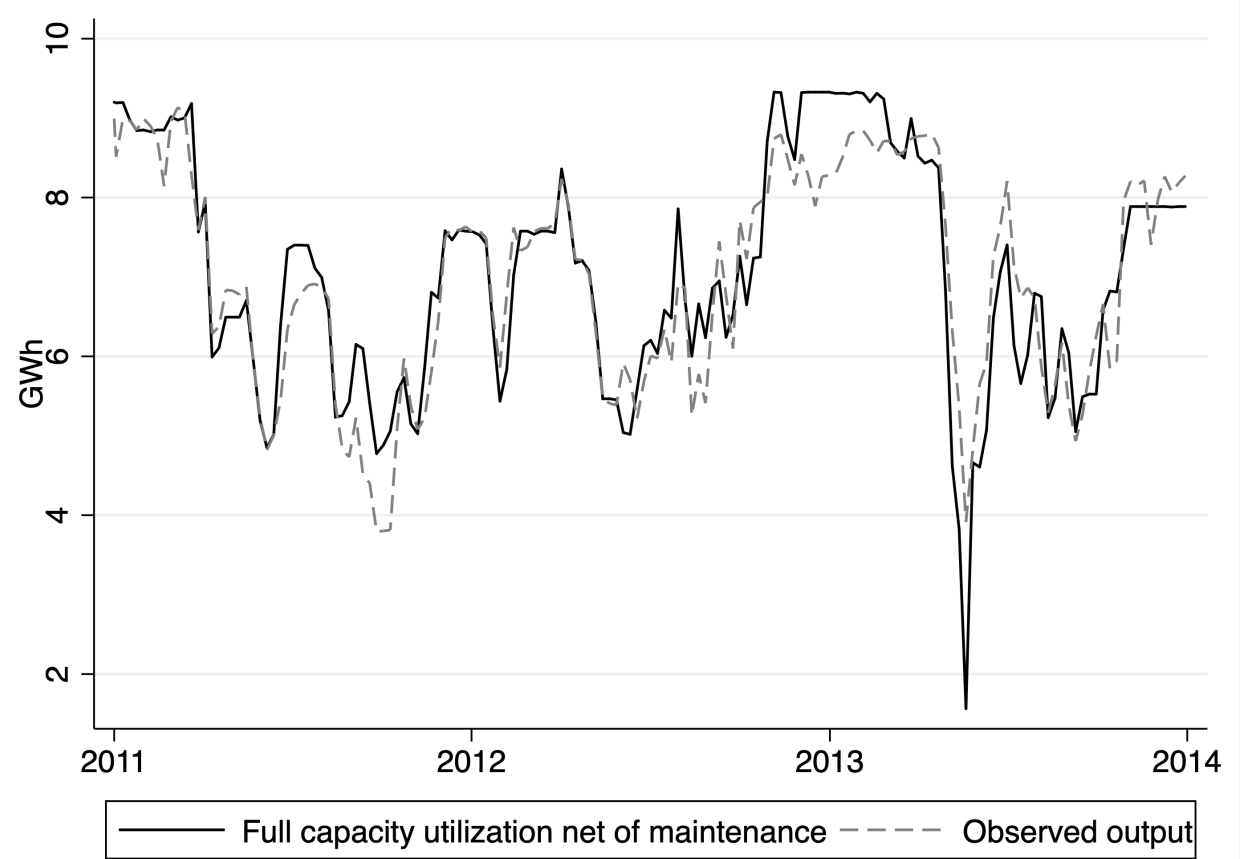

Note: Mean weekly aggregated nuclear output under the assumption that all plants would operate at full capacity except during outages reported as maintenance. 
Figure A6: Full capacity utilization net of outages reported as failures

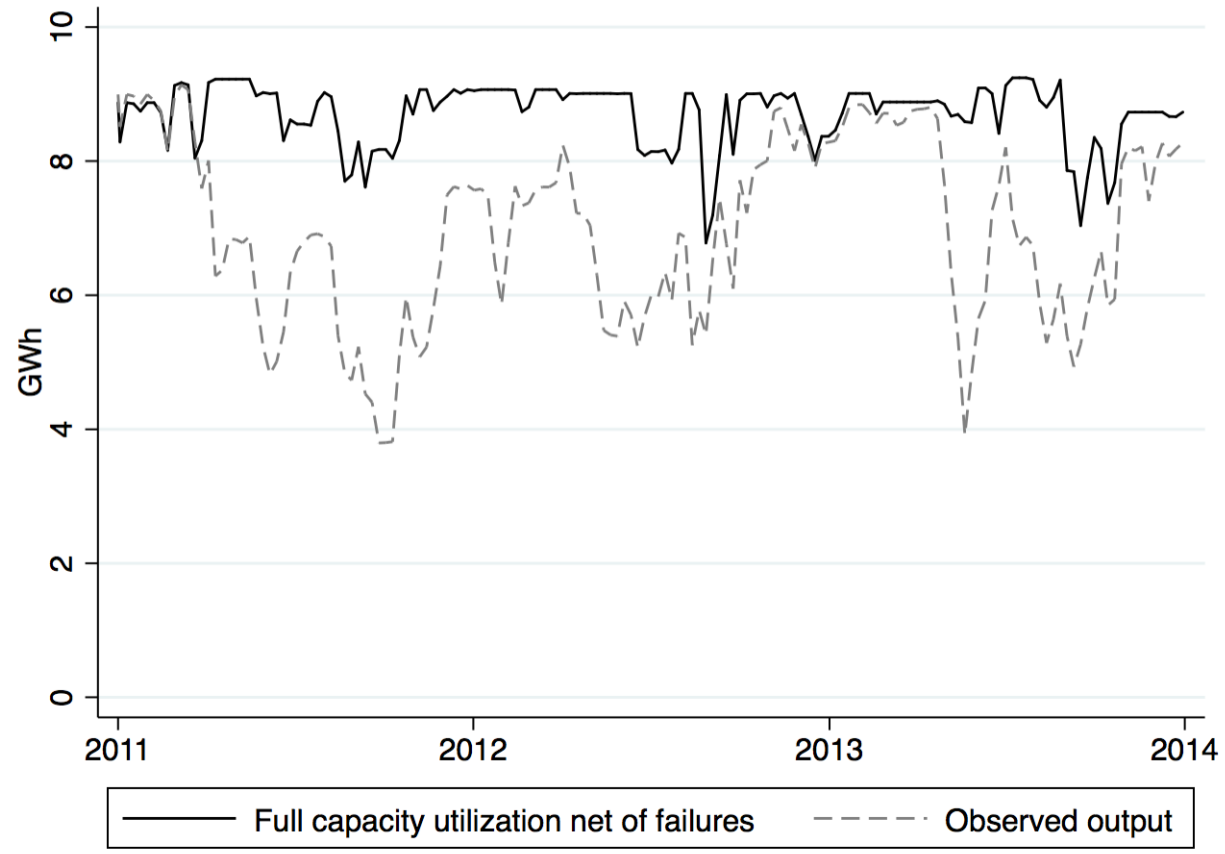

Note: Mean weekly aggregated nuclear output under the assumption that all plants would operate at full capacity except during outages reported as failures.

Figure A7: Swedish capacity factors 1990-2014

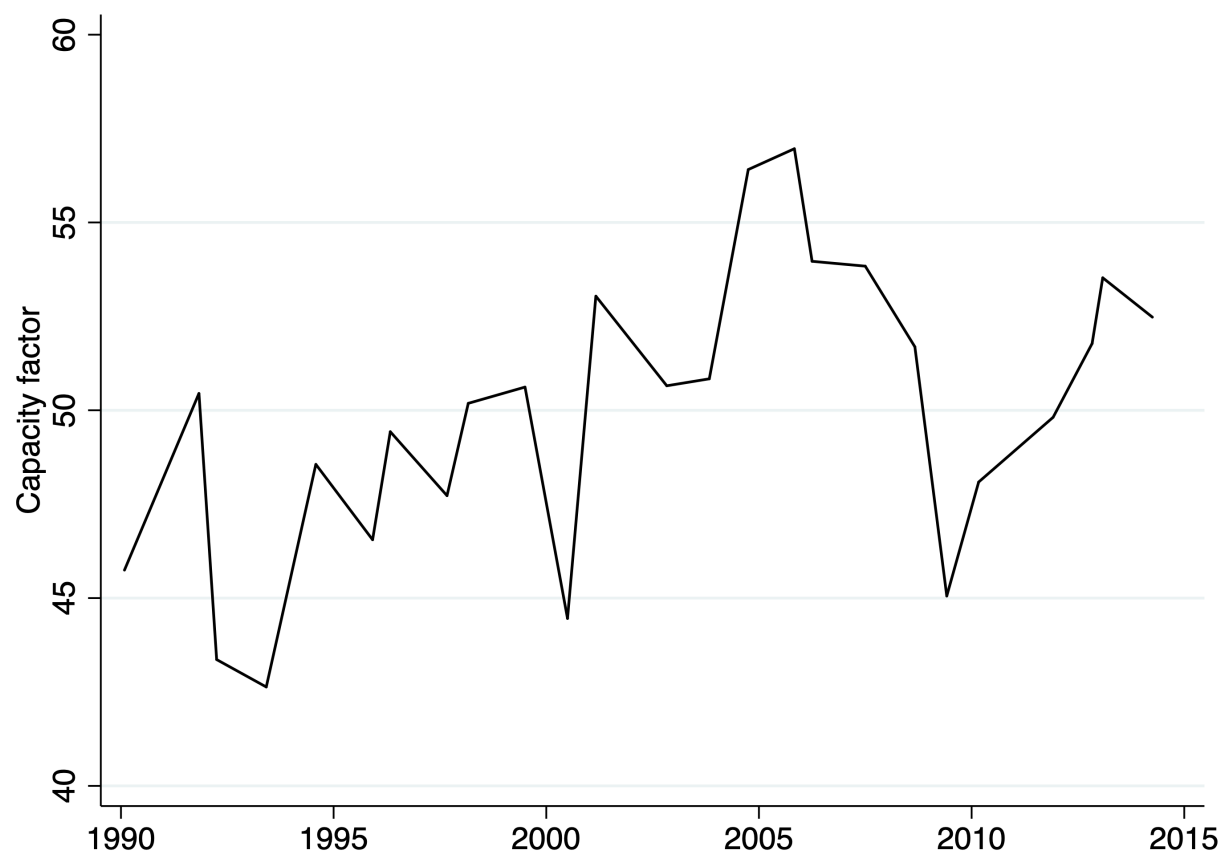

Note: Aggregate Swedish nuclear capacity factors 1990-2014 for all reactors. 
Figure A8: DiD placebo estimates

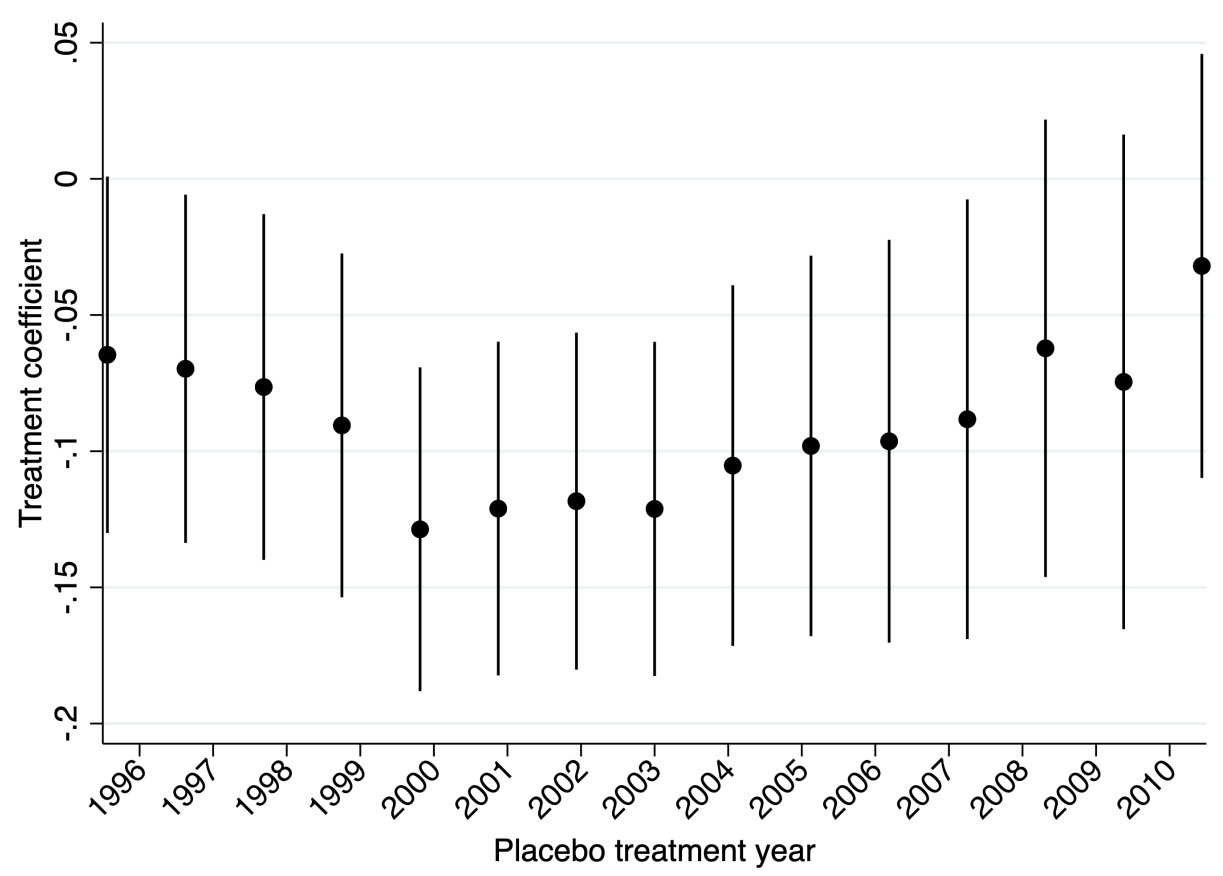

Note: Placebo estimates of the DiD specification (3) in Table 4 when varying the year of treatment between 1996-2010.

Figure A9: Density plot of the inverse residual demand slope

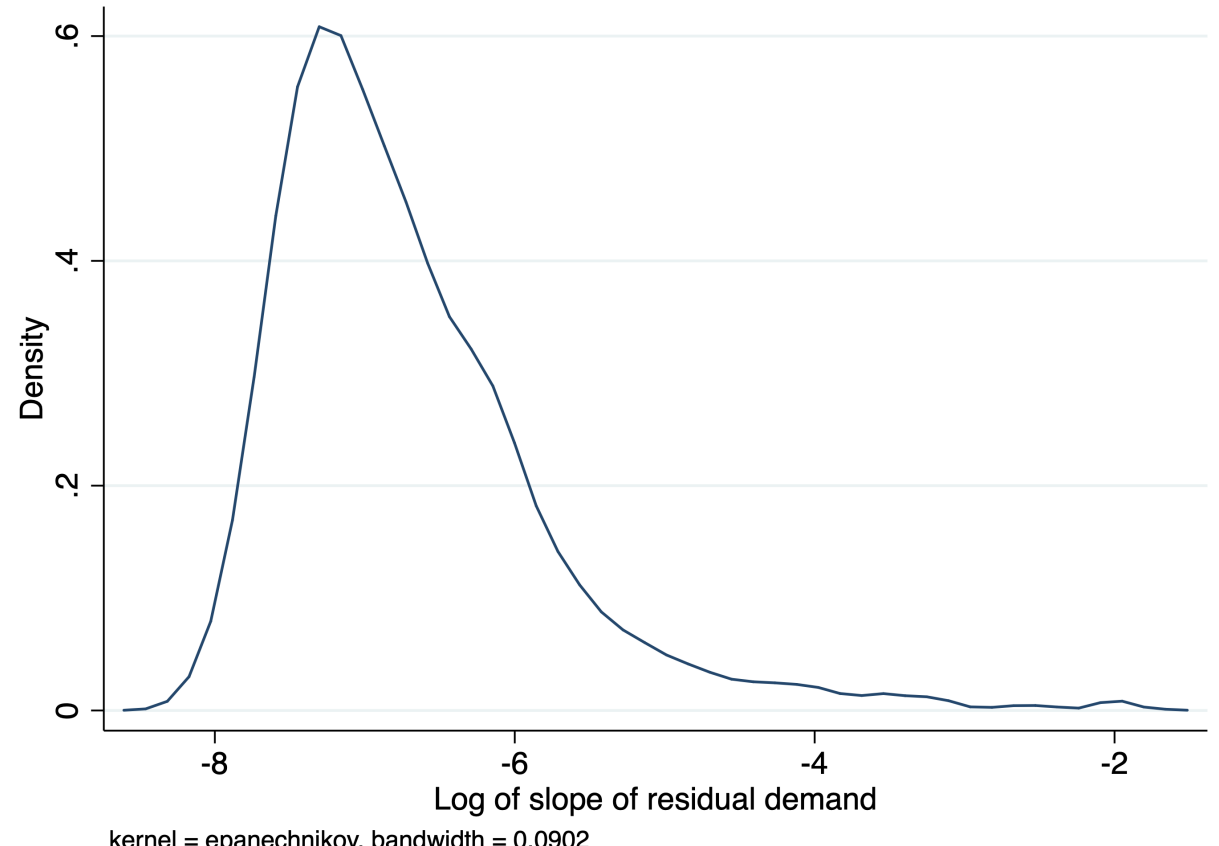

Note: Density plot of the logarithm of the slope of the inverse residual demand function facing the nuclear plants. 
Figure A10: Estimated forward sales

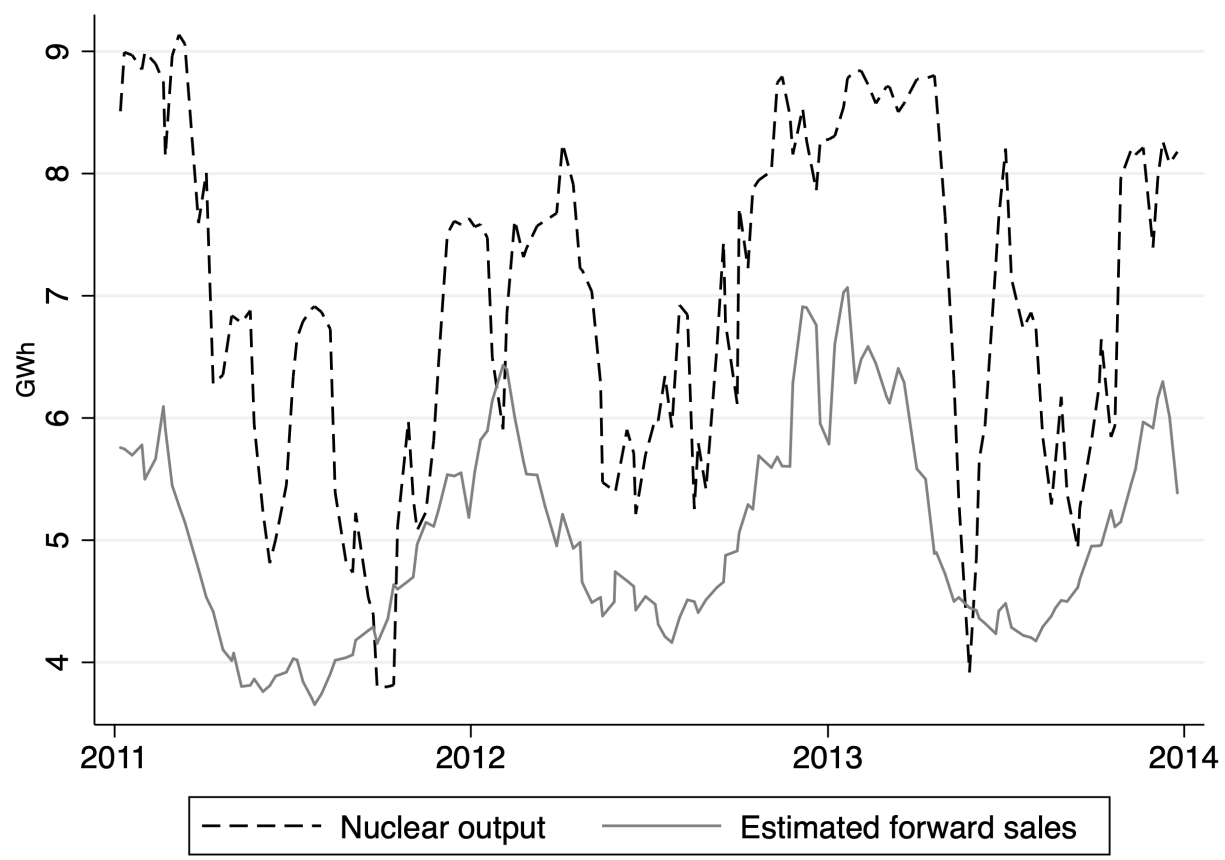

Note: Estimated forward sales under the divested solution (solid line) and observed nuclear output (dashed line). 
Figure A11: Collusion, monthly output

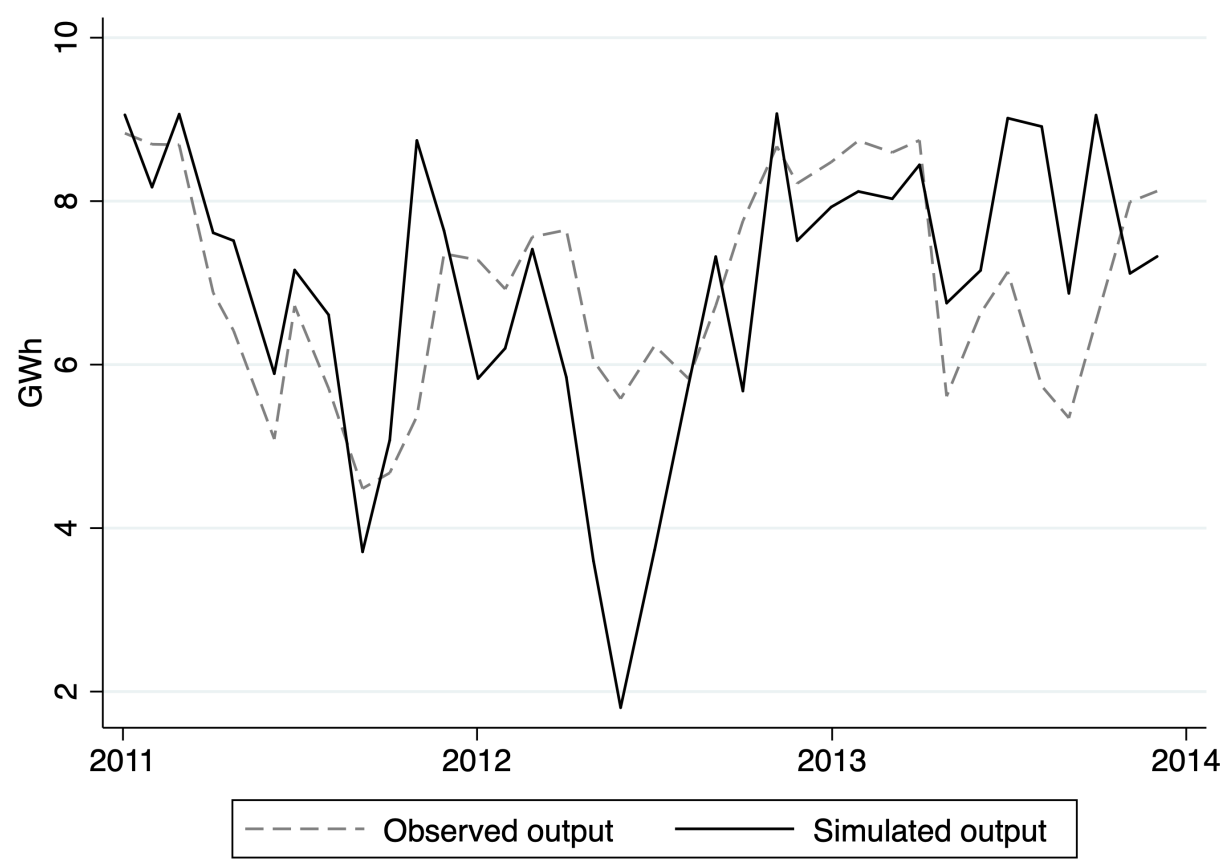

Note: Simulated output (solid line) and observed output (dashed line) given collusive behavior.

Figure A12: Cournot, monthly output

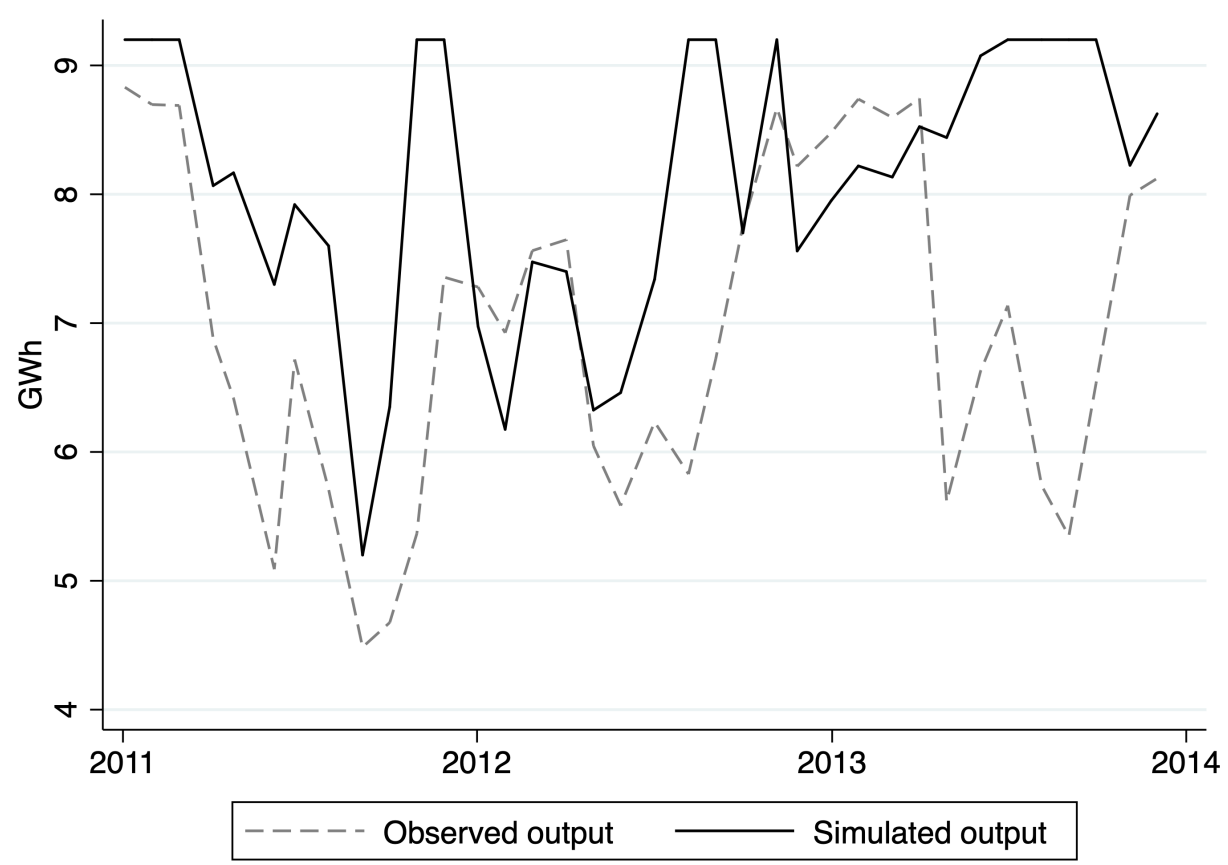

Note: Simulated output (solid line) and observed output (dashed line) given Cournot competition. 
Figure A13: Divested solution, monthly output

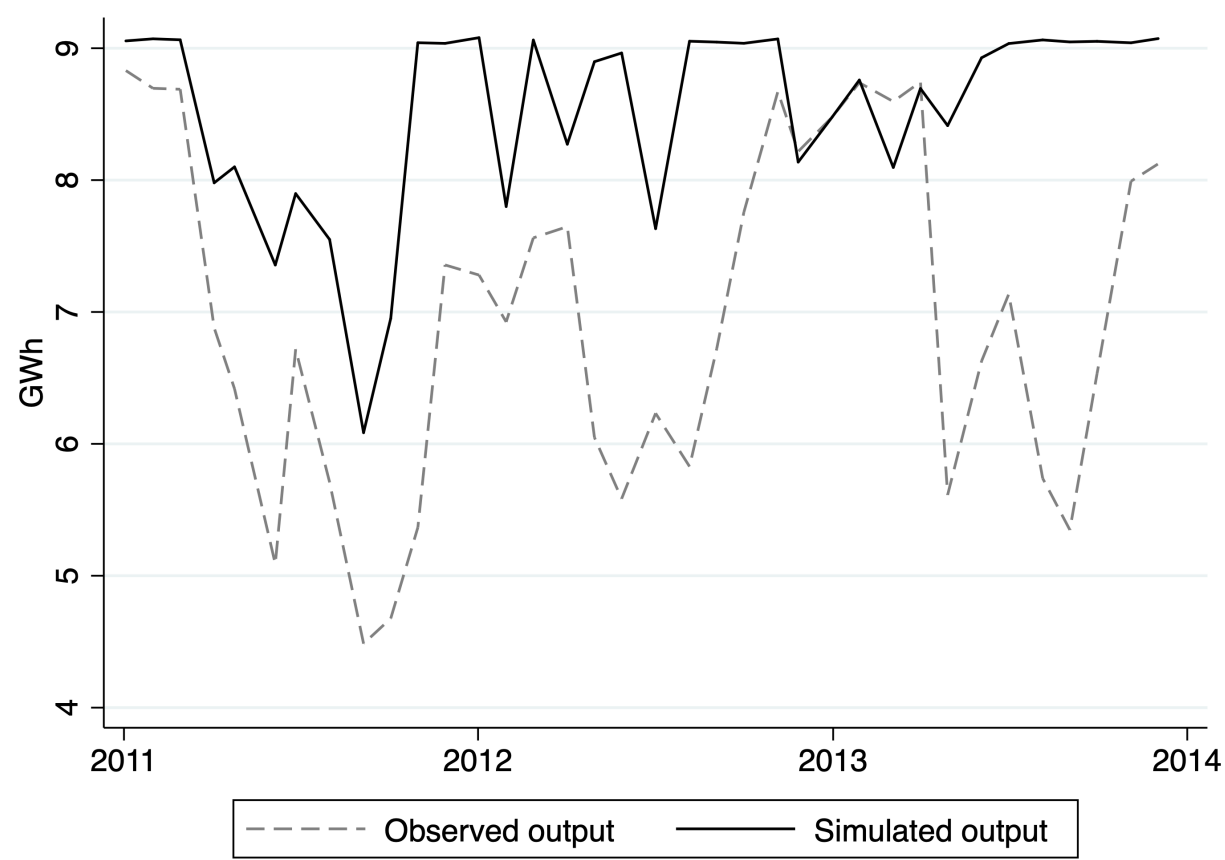

Note: Simulated output (solid line) and observed output (dashed line) under the divested solution.

Figure A14: Collusion, weekly output

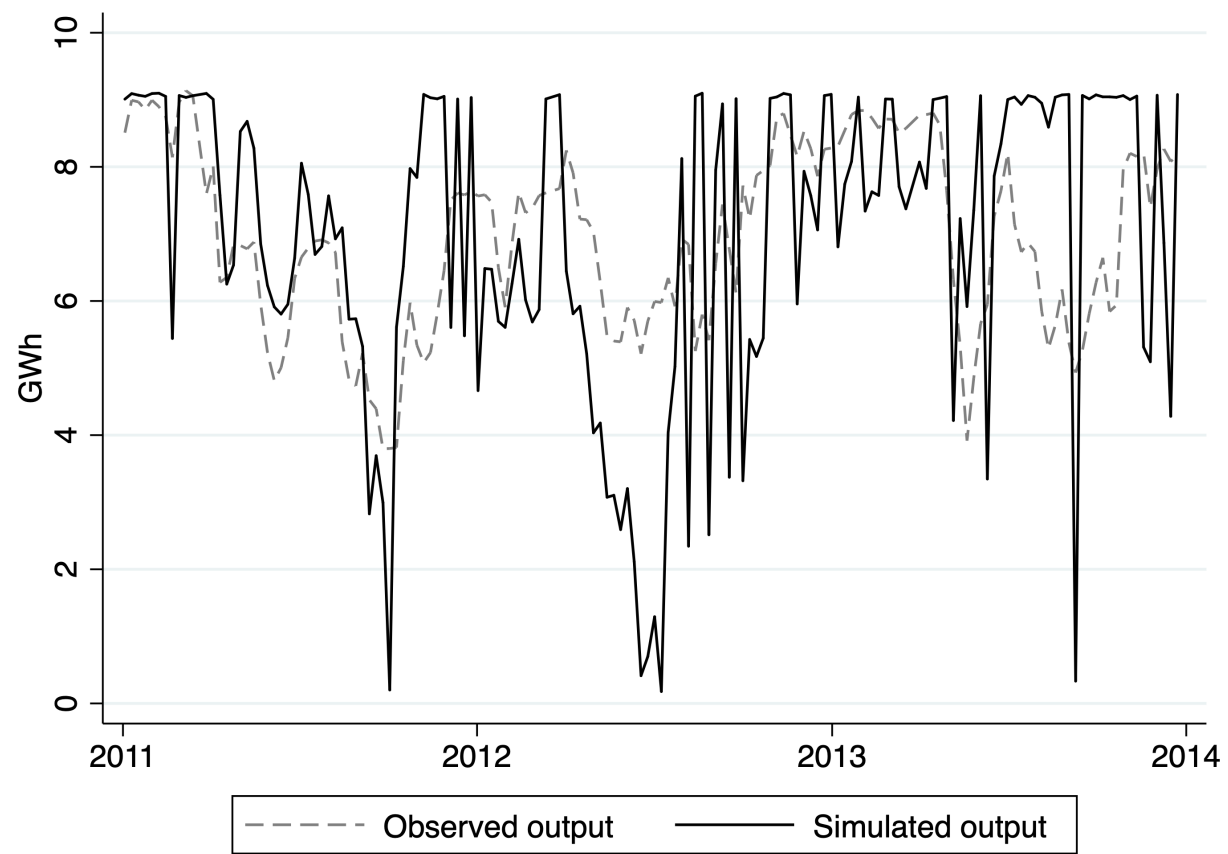

Note: Simulated output (solid line) and observed output (dashed line) given collusive behavior. 
Figure A15: Cournot, weekly output

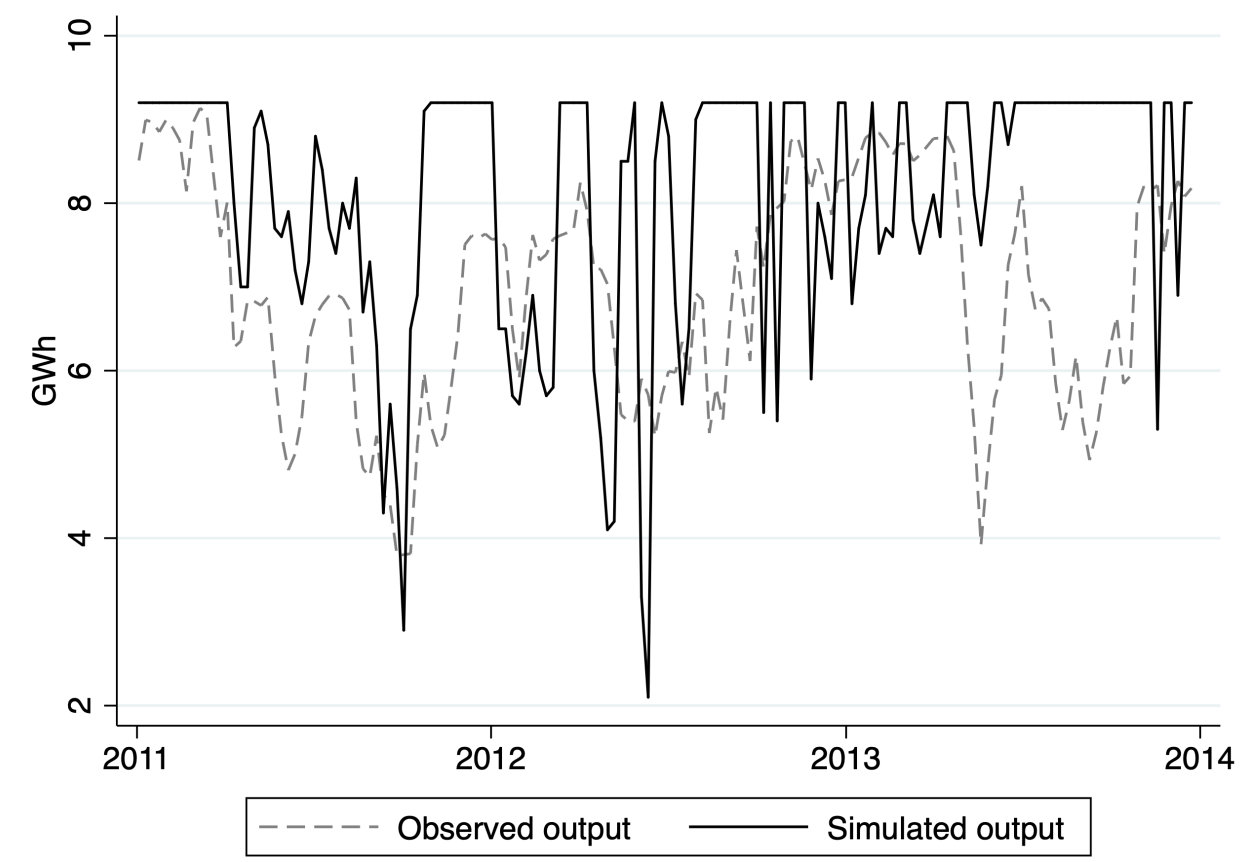

Note: Simulated output (solid line) and observed output (dashed line) given Cournot competition.

Figure A16: Divested solution, weekly output

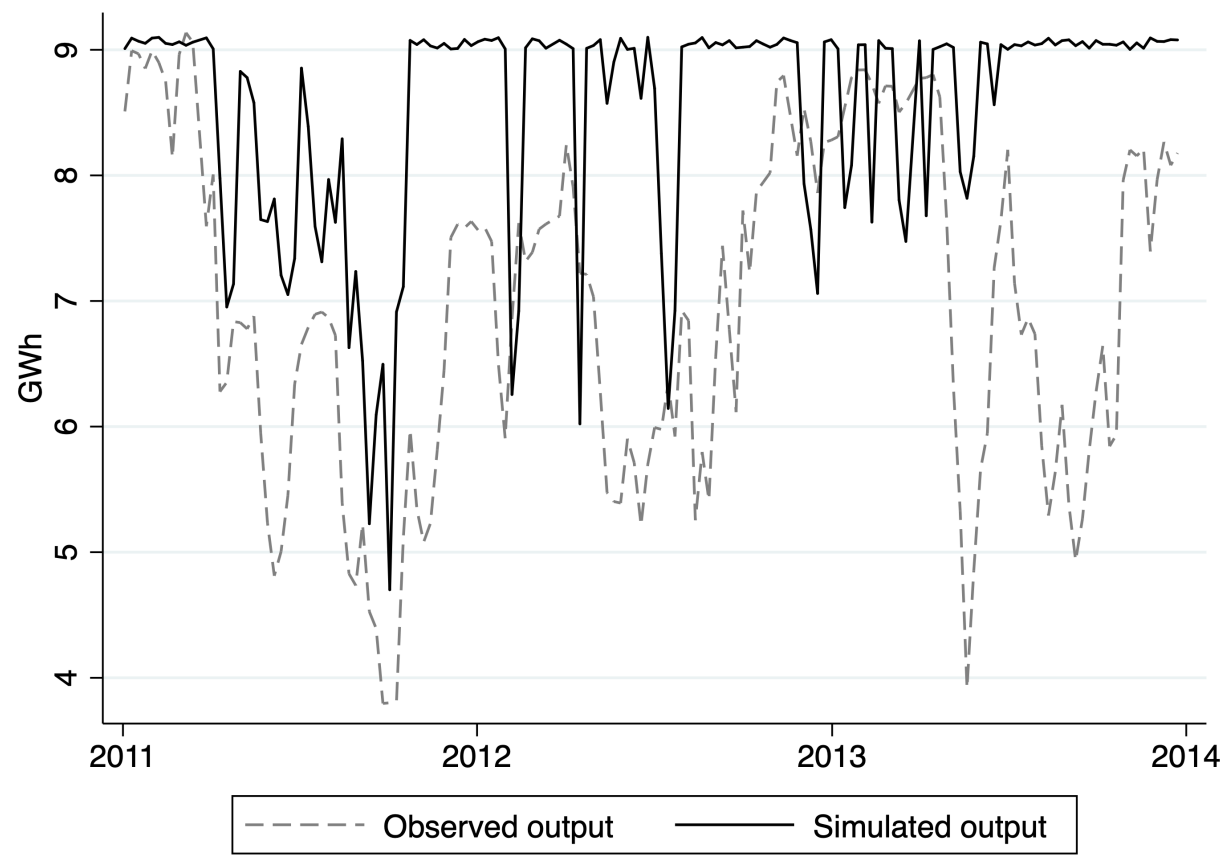

Note: Simulated output (solid line) and observed output (dashed line) given the divested solution. 
Figure A17: Hybrid solution, monthly output

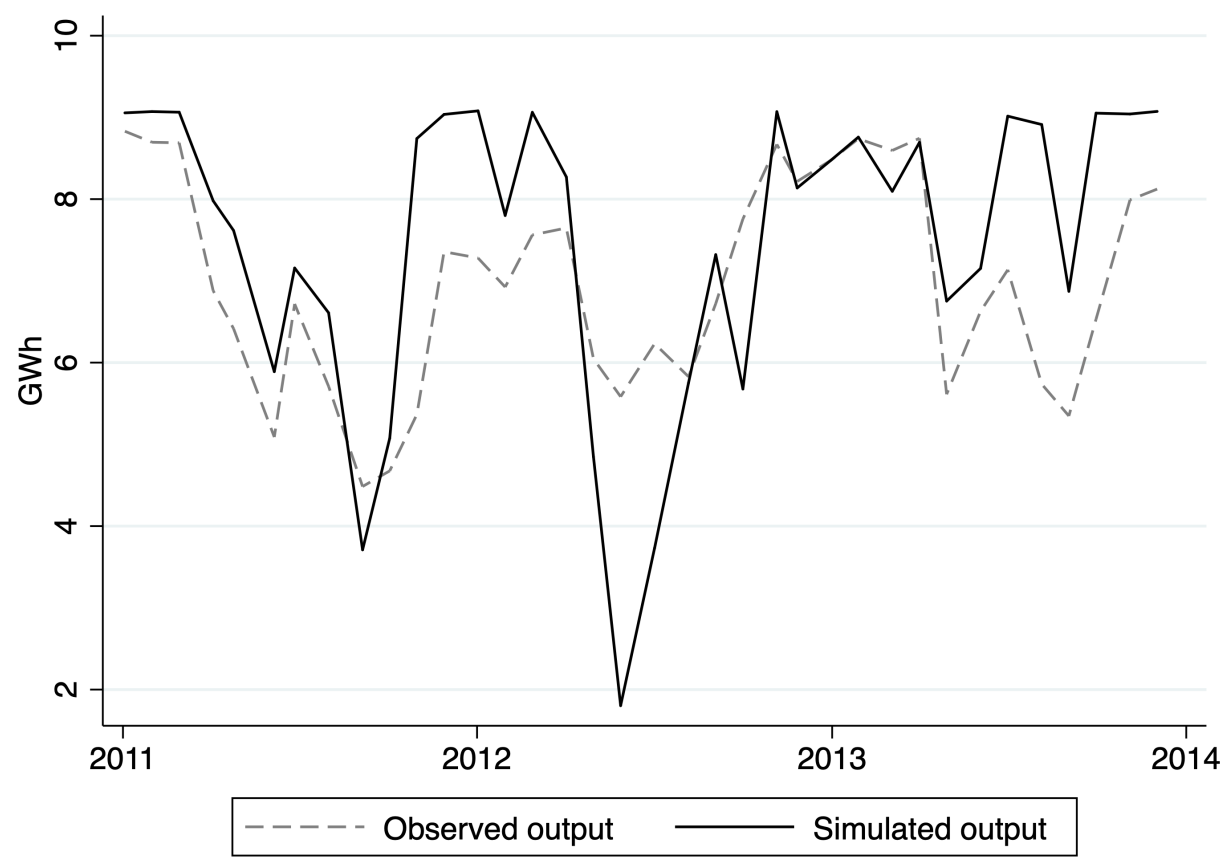

Note: Simulated output (solid line) and observed output (dashed line) given the hybrid model.

Figure A18: Sensitivity static specification
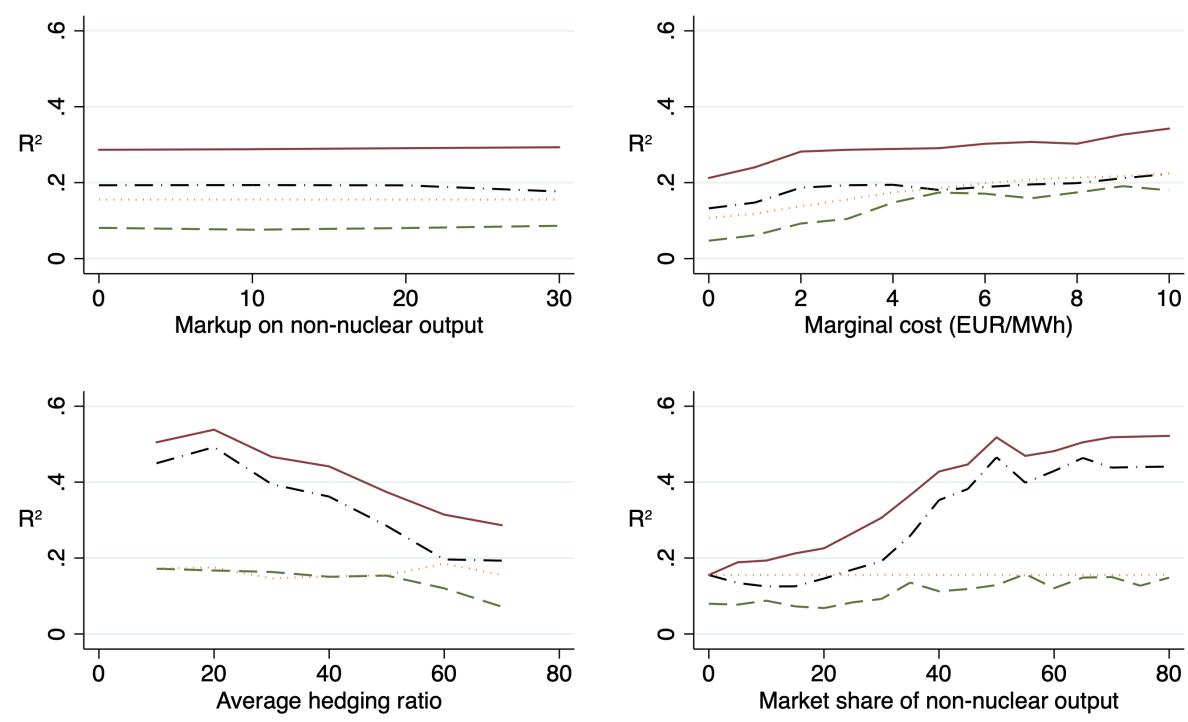

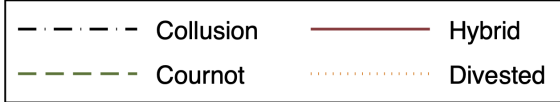

Note: $R^{2}$ as a function of parameter values when regressing observed output on simulated output according to eq. (17) under the static specification. Markups, hedging ratios, and market shares are in percent. Marginal cost is in EUR/MWh. 
Figure A19: Sensitivity dynamic specification
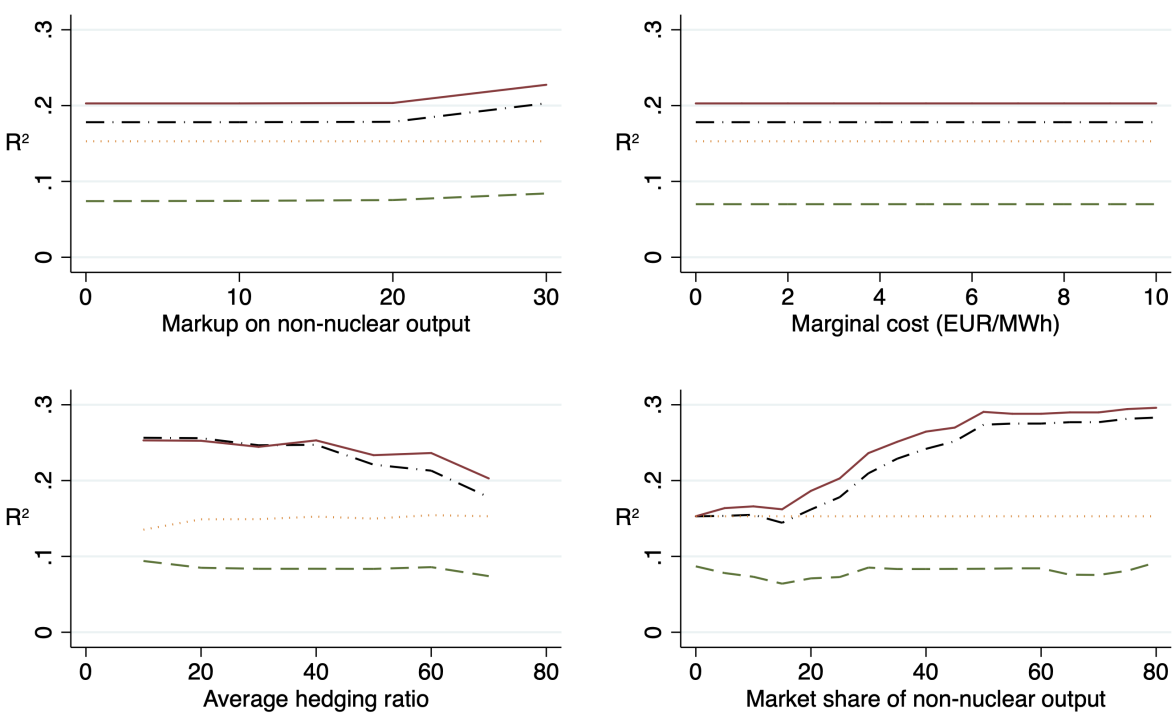

$$
\begin{array}{|lll}
\hline---\cdots \text { Collusion } & & \text { Hybrid } \\
----- \text { Cournot } & \ldots \ldots \ldots \ldots & \text { Divested } \\
\hline
\end{array}
$$

Note: $R^{2}$ as a function of parameter values when regressing observed output on simulated output according to eq. (17) under the dynamic specification. Markups, hedging ratios, and market shares are in percent. Marginal cost is in EUR/MWh.

Figure A20: Examples of profit functions
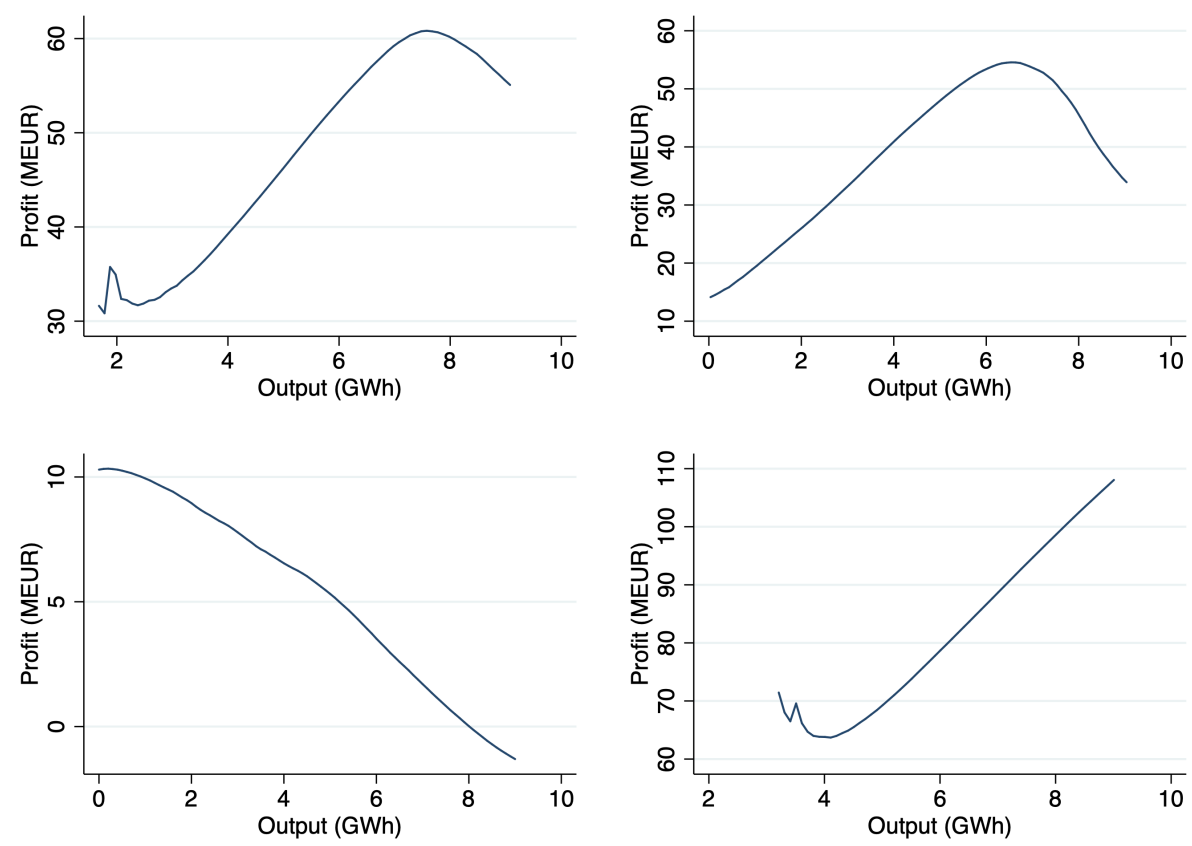

Note: Examples of weekly profit functions under the collusive model. 


\section{Appendix B. Solution technique}

To solve for optimal output under each behavioral assumption, I start by discretizing the optimization problem by fitting the hourly residual demand functions in blocks of 100 MWh. Since total installed nuclear capacity is $9.1 \mathrm{GWh}$, the resulting residual demand curve has 91 price/quantity pairs.

Maximal collusion and divested solution. These models are univariate optimization problems, and to solve for optimal output I begin by computing the profit for each point on the residual demand function during each hour of the sample. Since nuclear quantity is constrained to be constant during each week, I then compute the weekly profits for each possible quantity, i.e., there will be 91 profit/quantity pairs associated with each of the 156 sample weeks. Figure A20 depicts a set of weekly profit functions under the collusive model. As seen in the figure, the weekly profit functions are not always concave, so a first-order solution technique is not appropriate. Instead, I directly search for the profit maximizing quantity during each week.

To solve for optimal output under the dynamic extension, I construct profit functions for each possible combination of quantities associated with each of the 78 two-week periods in the sample. Since the quantity in week $2 z+1$ is directly determined by the quantity in the previous week, I then search for the combination of quantities that maximizes profits during each consecutive two-week period.

Cournot competition. The Cournot equilibrium is solved by first computing the bestresponse function for each firm (Vattenfall and E.ON) during each separate sample week. Hence, I compute the residual demand function given every possible quantity of the competitor, compute the associated profits, and search for the profit maximizing quantity. Using these best-response functions I then search for the equilibrium point, i.e., where the best-response functions of both firms intersect. In some instances there are multiple equilibria, due to the non-concavity of some of the profit functions. Since I want to test whether there exists some Cournot equilibrium that is consistent with the observed quantities, I then proceed by searching for the equilibrium with the smallest deviation from observed output. I compute the deviation as the sum of the (absolute) deviations between the simulated and observed quantity for both firms $i$ and $j$, i.e., deviation $=\left|q_{o b s}^{i}-q_{\text {sim }}^{i}\right|+\left|q_{o b s}^{j}-q_{\text {sim }}^{j}\right|$.

To solve the dynamic extension of the Cournot model, I compute the best-response for every possible quantity combination of the competitor during each of the 78 two-week periods. That is, each point on a best-response function will be associated with four quantities: two for the competitor and two for the own output. Since the quantity in week $2 z+1$ is directly determined by the quantity in the previous week, this results in 78 response functions for each firm. I then proceed by finding the equilibrium point as in the static case. Under the dynamic extension, there are also a few instances where no equilibrium is found. For each firm, I then search for the quantity pair that maximizes profits given the observed output of the other firm during that two-week period. 